\title{
EVOLUCIÓN DEL DERECHO INTERNACIONAL SOBRE LA INFANCIA*
}

\author{
EVOLUTION OF INTERNATIONAL \\ LAW REGARDING CHILDHOOD
}

\author{
Sergio Alejandro Rea-Granados** \\ Fecha de recepción: 24 de noviembre de 2016 \\ Fecha de aceptación: 1 de diciembre de 2016 \\ Disponibilidad en línea: 30 de diciembre de 2016
}

\begin{abstract}
PARA CITAR ESTE ARTículo/To CITE THIS ARTICle
Rea-Granados, Sergio Alejandro, Evolución del derecho internacional sobre la infancia, 29 International Law, Revista Colombiana de Derecho Internacional, 147-192 (2016). http://dx.doi.org/10.11144/ Javeriana.il 14-29.edis

doi:10.11144/Javeriana.i114-29.edis
\end{abstract}

* Artículo de Investigación, financiado por la Comisión Nacional de Investigación Científica y Tecnológica, CONICYT-PCHA/Doctorado Nacional/2016-21160698.

** Doctorado (c), Universidad de Chile. Maestría en Derecho Internacional, Universidad de Melbourne. Licenciatura, Universidad Iberoamericana, Ciudad de México. Orcid: http://orcid. org/0000-0003-2672-8676. Coordinador de la Maestría en Derechos Humanos, Comisión de Derechos Humanos del Distrito Federal. Ciudad de México, México. Contacto: rea_sergio@ hotmail.com 


\section{RESUMEN}

Este trabajo de investigación tiene como objetivo conocer los antecedentes y la evolución internacional histórica en el reconocimiento de los derechos de la niñez que dieron origen al principio de interés superior mediante el método dogmático para entender su significado, naturaleza y alcance, que posteriormente fue adoptado por el derecho internacional a favor de la protección de los derechos de los niños.

Palabras claves: Derecho internacional de los derechos humanos; derechos de la niñez; relación entre las diferentes ramas del derecho internacional y principio del interés superior de la niñez 


\section{ABSTRACT}

The purpose of this research is to know the background and international historical evolution in regards to the recognition of the rights of children that gave rise to the principle of children's best interests-using the dogmatic method as to understand its meaning, nature, and scope-which was later adopted by International law for the protection of the rights of children.

Keywords: International Human Rights Law; the Rights of the Child; Relationship between the branches of international law and the principle of the best interest of the child

\section{SUMARIO}

InTRoducción.- I. DesarRollo históRico del CONCEPTO DE LA NIÑEZ.- II. Convención sobre Derechos del Niño.- III. Corpus juris en materia de DERECHO DE LA INFANCIA.- IV. COMPATIBILIDAD DEL DERECHO INTERNACIONAL DE LOS DERECHOS A FAVOR DE LA NIÑEZ.- V. LOS PRINCIPIOS VINCULADOS CON LOS DERECHOS DE LA NiÑEZ.- CONCluSión.- Bibliografía. 
INTRODUCCIÓN

Debido a la importancia de la temática de la infancia y de brindar protección a todos los niños, la Convención sobre Derechos del Niño de 1989 (en adelante, CDN) ${ }^{1}$ se erige como una síntesis de las normas provenientes de instrumentos de derechos humanos de carácter general con principios y derechos propios de la tradición jurídica vinculada a los derechos de la infancia. La CDN concibe a las niñas, niños y adolescentes no solo como sujetos de medidas de protección y asistencia, sino como titulares de derechos propios y como actores de su propia vida y, por lo tanto, con la capacidad y el deber de participar en sus asuntos que les afectan.

Sin embargo, para poder entender estos derechos, el proceso de reconocimiento internacional tuvo que pasar por un largo camino en la historia de la humanidad, así como aquellas circunstancias que orillaron a su pleno reconocimiento en los tratados internacionales en materia de niñez y derechos humanos. Tomando en consideración lo anterior, este trabajo de investigación tiene por objeto analizar la evolución histórica de los derechos de la niñez desde sus orígenes hasta su reconocimiento por los principales instrumentos internacionales en la materia.

\section{Desarkollo históRico Del CONCEPTO DE LA NiÑEZ}

Durante el siglo XX comenzaron a tener mayor relevancia los derechos de los niños en el derecho internacional al reconocerlos como sujetos plenos de derechos y dejar a un lado los anteriores conceptos de compasión, tutela o represión. Los derechos de la infancia han evolucionado en el tiempo.

En primer término, la infancia en el Derecho Romano tenía una situación jurídica meramente privada, pues el pater familias

\footnotetext{
1 Organización de las Naciones Unidas, Asamblea General, Convención sobre Derechos del Niño, adoptada y abierta a la firma y ratificación por la Asamblea General en su Resolución 44/25, 20 de noviembre de 1989, entrada en vigor 2 de septiembre de 1990. Disponible en: http://www. hchr.org.co/documentoseinformes/documentos/html/pactos/conv_derechos_nino.html
} 
era quien ostentaba los derechos de los menores de edad en temas relacionados con la patria potestad, capacidad jurídica, bienes y derechos sucesorios ${ }^{2}$. De esta forma, el infante estaba sometido a la potestad del pater familias, quien era el único integrante de la familia con plena capacidad de goce y ejercicio o sui iuris. Contrario a esto, el infante era considerado un ser vulnerable y sin uso de razón durante los primeros años. Además, este derecho concebía a los infantes como propiedad de terceros, padres o comunidad política ${ }^{3}$. De esta forma, podemos visualizar que para este derecho, la condición del "niño" está íntimamente vinculada con la condición de "hijo" por lo que resulta difícil establecer el trato que obedecía a la calidad de infante o al hecho de la filiación ${ }^{4}$.

También, en el Derecho Romano, había otras leyes que trataban temas relacionados con los menores de edad, por ejemplo: en la época de las Siete Partidas [siglo XIII], se promulgó la Ley 8, título 17 de la Partida IV, la cual facultaba al pater familias para vender y empeñar a sus hijos ${ }^{5}$.

La Edad Media no fue una época favorable al tratamiento jurídico a favor de la niñez. En primer lugar, porque durante esta época no se reconocía la dignidad de las personas ni se estudiaban las cualidades humanas como parte fundamental del centro de las preocupaciones del derecho y de la vida social. Esta situación afectó el reconocimiento de sus derechos por parte del Estado a diversos grupos, entre ellos los infantes ${ }^{6}$. En segundo

2 José Miguel Piquer-Marí, Apuntes generales sobre la situación jurídica y la protección del menor en el derecho romano, en La protección del menor, 339-371 (Antonio Vallés, dir., Tirant lo Blanch, Valencia, 2009).

3 Mónica González-Contró, Mauricio Padrón-Innamorato, Daniel Márquez-Gómez, Rosío Arroyo-Casanova \& Pastora Melgar-Manzanilla, Propuesta teórico-metodológica para la armonización legislativa desde el enfoque de derechos de niñas, niños y adolescentes (Instituto de Investigaciones Jurídicas de la Universidad Nacional Autónoma de México, UNAM, México, 2012).

4 Ibíd., p. 5.

5 María Jesús Coronado-Buitrago, Compatibilidad del derecho internacional con los derechos a favor de la niñez: evolución jurídica de los derechos de la infancia, en Exposición de los derechos del niño (Carmen Sánchez-Moro, coord., Ministerio de Asuntos Sociales, Madrid, 1989).

6 Karel Vasak, Las dimensiones internacionales de los derechos humanos, Vol. I, 38 (Hernán Sabaté y María José Rodellar, trads., Editorial Serbal, Barcelona, 1984). 
lugar, las preocupaciones legales fundamentales se basaban en el fortalecimiento del Estado y en su soberanía, lo cual dejaba a un lado el tema de la protección de los derechos humanos y en especial los derechos a favor de la infancia. Debido a ello, la visión social que se tenía sobre los niños era que cumplían un papel económico dentro de su familia y esta situación provocó el elevado índice de mortalidad al no contar con la protección de los progenitores ni del Estado. A pesar de esto, la situación se agravaba, cuando se trataba de niños no reconocidos dentro del matrimonio, que enfrentaban mayores abusos y violaciones a su esfera jurídica. En el caso de las niñas, debido a que desde la perspectiva de vida de una sociedad predominantemente militar y agrícola, no se les atribuía ningún valor económico ni social, su supervivencia y sus derechos eran muy poco tomados en cuenta. En general, en lo que respecta a esta época de la humanidad, la situación de los niños no tuvo mayor relevancia, si bien con el advenimiento del cristianismo se proscribieron todas aquellas prácticas contrarias a estos, y a partir del siglo XIV, algunos autores suponen que se comienza a conceder cierta importancia a la infancia?.

En el siglo XVIII, en el derecho inglés surgió el concepto de bienestar del niño (welfare principle), el cual fue de gran trascendencia pues brindó ciertos beneficios de protección a la niñez. Debido a ello, las cortes inglesas afirmaban que el principio del bienestar de la niñez debería ser una consideración relevante junto con otras situaciones como el deseo o voluntad de los progenitores $^{8}$.

Sin embargo, esta figura se centraba en el campo del derecho privado y dejaba a un lado otras situaciones del derecho público, sobre todo cuando el Estado es también responsable de brindar protección. A pesar de esto, cabe señalar que en Gran Bretaña la relación jurídica del progenitor con los hijos continuaba siendo

7 Philippe Ariès, La infancia, 281 Revista de Educación, 5-17 (1986). Disponible en: http://www. mecd.gob.es/revista-de-educacion/numeros-revista-educacion/numeros-anteriores/1986/re281. html, http://www.mecd.gob.es/dctm/revista-de-educacion/numeros-completos/re28100507. pdf?documentId $=0901 \mathrm{e} 72 \mathrm{~b} 813 \mathrm{c} 4502$

8 Francisco Rivero-Hernández, El interés del menor, 27 (Dykinson, Madrid, 2007). 
parte del ámbito de los derechos de propiedad, lo cual dejaba fuera los deseos y voluntades del menor de edad. Es decir, el derecho inglés solo consideraba a los infantes como instrumentos de uso para los progenitores y no les daba un tratamiento como persona humana ${ }^{9}$. En este sentido, para Miguel Cillero-Bruñol, este concepto se veía reflejado en la aplicación del derecho de equidad como alternativa al derecho consuetudinario que solo consideraba a la niñez como un instrumento para el uso de los progenitores $^{10}$.

A pesar de esta situación, también hay repertorios de la jurisprudencia inglesa, en los cuales el tribunal deniega el habeas corpus con base en el argumento: "bienestar del niño (welfare)"11. Es decir, las cortes inglesas reconocían la figura del bienestar de la niñez, pero con la perspectiva de seguir considerando al menor como objeto de protección y no como sujeto de derechos.

Posteriormente, durante el proceso de industrialización, que tuvo lugar a mediados del siglo XIX, se produjo una transformación en el sistema de producción basado en fábricas textiles, manufacturas y minas para la obtención de carbón. Esta forma de producción generó condiciones específicas de trabajo que causaron daños y perjuicios a las personas menores de edad, quienes debido a su condición física y ausencia de protección legal fueron empleados en estas industrias. Debido a esta situación, se empezaron a aprobar leyes que regulaban el trabajo precario y forzoso en las fábricas textiles y de carbón. La legislación también fue llamada Factory Acts. Una de las leyes que comprendía esta legislación era la Ley para la Mejor Conservación de la Salud y de la Moral de los Aprendices, de 1802. Esta legislación limitaba el empleo de los niños a horas extremas, mas no el tra-

9 Savitri Goonesekere, The Best Interests of the Child: South Asian Perspective, 8 International Law Policy Family, 1, 117-149 (1994). Disponible en: http://digital.lib.ou.ac.lk/docs/ bitstream/701300122/1322/1/The\%20Best\%20Interest\%20of\%20the\%20Child.pdf

10 Miguel Cillero-Bruñol, El interés superior del niño en el marco de la Convención Internacional sobre los Derechos del Niño, en Infancia, Ley y Democracia en América Latina, 69-85 (Emilio García-Méndez \& Mary Belloff, comps., Ediciones Temis, Ediciones Desalma, Bogotá, Buenos Aires, 1998). Disponible en: https://ecaths1.s3.amazonaws.com/tfi/1011729881.texto\%20 CILLERO\%20BRU\%C3\%91OL.pdf

11 Rex v. Delaval, 1763; Rex v. De Manneville, 1804 y, sobre todo, el caso Blisset de 1774. 
bajo forzoso ni peligroso. En 1819, se aprobó la Ley Reguladora de las Fábricas de Algodón, también llamada Peel Law, la cual prohibió el empleo de personas menores de 9 años de edad ${ }^{12}$.

Paralelamente, en la parte continental, a mediados del siglo XIX comenzaron a surgir ideas sobre derechos especiales a favor de la niñez. En Francia, a partir de $1841^{13}$, comenzaron a surgir leyes que protegían este grupo de la población, debido a las condiciones dramáticas y precarias del trabajo infantil ${ }^{14}$. Por su parte, Paul Adams, Leila Berg, Nan Berger, Michael Duane, Alexander Sutherland Neill y Robert Ollendorff están de acuerdo con esta postura y señalan, por ejemplo, que ninguna parte de la legislación fabril ni educacional afectó las relaciones entre el menor de edad y sus progenitores. La única Ley que protegía al niño en el hogar fue la Ley de Reformas a la Ley de los Pobres, promulgada en 1868, que daba disposiciones para el castigo al padre si se demostraba que la salud del niño había sido seriamente afectada por no haberle proporcionado el abrigo y manutención adecuados. Esta ley no era buena protección. No era fácil convencer a los magistrados de que deberían castigar a los padres, salvo por las situaciones más ultrajantes, y de cualquier forma era muy difícil resolver qué era un descuido y qué era incapacidad debida a la pobreza ${ }^{15}$.

12 John Towers Ward, Popular Movements c. 1830-1850 (John Towers Ward, ed., MacMillan, London, 1970). John Towers Ward, The Factory Movement, 1830-1855 (MacMillan, London, 1962).

13 Ley del 22 de marzo de 1841 que regulaba el trabajo de los niños. La ley fijó algunos límites de forma que protegían a los niños; pero, al mismo tiempo, legalizó su explotación: prohibió el trabajo para los menores de 8 años, lo limitó a 8 horas diarias para los niños entre 8 y 12 , y a 12 horas para los mayores de 12 . Además, la ley puntualizaba que todos los niños de menos de 12 años debían ir a la escuela. Francia, Loi du 22 mars de 1841, relative au travail des enfants employés dans les manufactures, usines ou ateliers. Disponible en: http://travail-emploi.gouv. fr/IMG/pdf/loi_22_mars_1841-2.pdf

14 Los niños eran obligados a trabajar trece horas completas, como instrumento de castigo se utilizaba el látigo, muchas veces en un ambiente antihigiénico (locales con escasa luz y nula ventilación), condiciones laborales precarias, en trabajos peligrosos y sin herramientas adecuadas para su seguridad, entre otras situaciones que ponían en riesgo su vida, integridad, salud, desarrollo físico, social y psicológico.

15 Paul Adams, Leila Berg, Nan Berger, Michael Duane, Alexander Sutherland Neill \& Robert Ollendorff, Los derechos de los niños, hacia la liberalización del niño, 220 (Julián Hall, comp., María Aurora Reyes de Baroco, trad., Editorial Extemporáneos, México, 1979). 
A partir de 1881, las leyes francesas garantizaron a los infantes el derecho a una educación. Por ejemplo, la Ley de 28 de marzo de 1882 señalaba que la educación debía ser gratuita, laica y obligatoria, situación que provocó una nueva era para la instrucción de los infantes ${ }^{16}$. Para Philippe Ariès, esta constituye la gran diferencia entre la civilización medieval y moderna y se encuentra en el centro de la construcción del concepto de niño: "El hecho esencial es el siguiente: la civilización medieval no tenía idea de la educación. Nuestra sociedad depende hoy día (y lo sabe) del éxito de su sistema educativo"17.

De igual forma, la Ley de 24 de julio de 1889 reguló la figura de la patria potestad, la cual por primera vez incorporó el concepto abstracto de interés del menor de edad en Francia ${ }^{18}$. Sin embargo, los efectos de esta ley solo comprendían la patria potestad de infantes maltratados o moralmente abandonados por los progenitores y no por otras acciones que afectaran su esfera jurídica ${ }^{19}$.

Uno de los primeros en formular e inspirar la defensa de la niñez fue Jules Vallès. En su obra L'Enfant (El Niño), narró abiertamente los métodos coercitivos y de violencia aplicados por los adultos contra los menores de edad, todo ello basado

16 De igual forma, esta ley señalaba que los niños entre 6 a 13 años debían ser escolarizados y los inspectores tenían la obligación de hacer respetar la ley. Francia, Loi du 28 mars de 1882, portant sur l'organisation de l'enseignement primaire. Disponible en: https://www.legifrance. gouv.fr/affichTexte.do;jsessionid=81B65BF14727E4047256DD3714A3902E.tpdjo16v_2?cidT exte $=$ LEGITEXT000006070887\&dateTexte $=19981221$

17 Philippe Ariès, La infancia, 281 Revista de Educación, 5-17 (1986).

18 Isaac Ravetllat-Ballesté \& Ruperto Pinochet-Olave, El interés superior del niño en el marco de la Convención Internacional sobre los Derechos del Niño y su configuración en el derecho civil chileno, 42 Revista Chilena de Derecho, 3, 903-934, 907 (2015). Disponible en: https:// dialnet.unirioja.es/ejemplar/427895

19 Ley 24 de julio de 1889. El párrafo 1 del artículo 17 dispone que cuando el servicio de ayuda social a la infancia, o asociaciones de beneficencia regularmente autorizadas a tal efecto, o particulares en el goce de sus derechos civiles, hayan aceptado el cuidado de los menores de dieciséis años que les hayan sido confiados por padres, madres o tutores autorizados por el consejo de familia, el tribunal del domicilio de esos puede, a demanda de las partes interesadas obrando conjuntamente, decidir que hay lugar, en interés del niño, a delegar los derechos de patria potestad, abandonados por los padres a favor del servicio de ayuda social de la infancia, o del establecimiento o del particular que guarda al niño. José María Castán-Vázquez, La reforma de la adopción en el derecho francés, 3 Anuario de Derecho Civil, 821-823, 822 (1963). Disponible en: https://www.boe.es/publicaciones/anuarios_derecho/abrir_pdf.php?id=ANUC-1963-30082100823. Francia, Loi du 24 juillet de 1889, sur la protection des enfants maltraités ou moralement abandonnés, placement des mineurs, action educative en milieu ouvert. 
en el contexto histórico y social de la época ${ }^{20}$. De igual forma, en este período, otros autores se sumaron a denunciar la falta de protección y cuidado de este grupo de personas en sus obras literarias, como Charles Dickens, que relataba en sus obras la precaria situación de la infancia ${ }^{21}$.

La evolución jurídica del Código Civil Napoleónico de $1804^{22}$, en el siglo XIX, inspiró la regulación de las relaciones familiares y sociales en Europa, que incluía preceptos específicos para los niños. Sin embargo, debido a la naturaleza de este cuerpo legal, la relación de los infantes continuó siendo competencia del derecho privado, pero, además, debido a que este cuerpo jurídico es de inspiración del derecho romano la relación del progenitor con los hijos continuaba teniendo una connotación patriarcal ${ }^{23}$. Esto debido a que de acuerdo con este Código el menor de edad no podía ejercer ningún derecho privado, su opinión no era en absoluto vinculante en materia de educación, ni podía escoger su religión ni abandonar su domicilio sin la autorización paterna ${ }^{24}$. Esta situación continuó generando problemas en contra de la infancia, tras el poder absoluto del progenitor sobre los hijos, que en ciertas ocasiones generaba abusos, explotación, malos tratos y abandono por parte de los progenitores ${ }^{25}$.

Debido a la falta de protección a favor de la infancia, en 1883 se realizó el primer Congreso Internacional de Protección a la

20 Jules Vallès narra la generalización del conflicto de los niños en la familia y en la escuela. En esta obra denuncia el sistema represivo de los institutos y critica el sistema educativo. Manuela San Miguel, Por la liberación del niño... Jules Vallès, 1 Revista Pedagogía de la Universidad de Salamanca, 57-67 (1985). Disponible en: http://revistas.usal.es/index.php/0214-3402/article/ view/516/689

21 Obras de Charles Dickens como Oliver Twist, David Copperfield y Cuento de Navidad denuncian la desesperanza de los niños en el siglo XIX.

22 Francia, Code Civil des Français, 21 mars de 1804. Disponible en: http://gallica.bnf.fr/ark:/12148/ bpt6k1061517

23 Cristina López-Sánchez, La responsabilidad civil del menor, 62-64 ( $2^{\mathrm{a}}$ ed., Dykinson, Madrid, 2003).

24 Jean Le Gal, Los derechos del niño en la escuela: una educación para la ciudadanía, 34 (Francesc Massana, trad., Editorial Graó, Barcelona, 2005).

25 Joaquín de Paul-Ochotorena, Diferentes situaciones de desprotección infantil, en Manual de protección infantil, 5 (María Ignacia Arruabarrena-Madariaga \& Joaquín de Paul-Ochotorena, Masson, Barcelona, 2001). El autor denuncia que la legislación francesa era deficiente debido a que la patria potestad se elevaba como muralla infranqueable para amparar la sevicia, la explotación y el abandono de gente indigna, que abusaban del hijo al inducirlo a la vagancia y el crimen. 
Infancia en París, con la perspectiva médica y científica de mejorar las condiciones higiénicas y de salud de la niñez, más que una visión jurídica para reconocer los derechos de la infancia. De esta manera, dos de los campos de mayor preocupación fueron la mortalidad y la desnutrición infantil. Además, este Congreso estuvo motivado por varios Estados que pertenecían a la Comunidad Europea, pues compartían problemas y circunstancias comunes. Debido a ello, la postura sobre el cuidado y la protección de la infancia se fijó y construyó originariamente desde la perspectiva histórica de lo que ocurría en Europa y no sobre la situación de este grupo de manera universal.

Lo anterior muestra el caos conceptual en la materia y la necesidad de clarificar las ideas que sirvieron de fundamento teórico de los derechos de la niñez, y el proceso histórico para el reconocimiento de los derechos de la infancia. En este sentido, Paul Adams, Leila Berg, Nan Berger, Michael Duane, Alexander Sutherland Neill y Robert Ollendorff consideran este período una época de estado latente, en que hay una negación de derechos que pudieran corresponder, debido a que para estos autores es evidente que los niños sí tienen derechos básicos en su infancia ${ }^{26}$. Al respecto, podemos señalar que durante esta etapa la infancia es sujeta de prestaciones, pero no es titular de derechos.

El siguiente proceso histórico se dio cuando cambió la comprensión del enfoque que se les otorgaba a los niños, a partir del siglo XX. Es decir, cuando comenzaron a materializarse instrumentos internacionales que reconocieron a la niñez como sujeto de derechos. Sobre todo cuando el infante fue considerado únicamente un renuevo de la estructura social y su valor estaba determinado por su pertenencia a una familia y como tal fue tratado en las primeras atribuciones de derechos subjetivos que lo excluyeron como titular individual, y lo incluyeron en la esfera paterna del "sui iuris-varón-propietario"27.

26 Paul Adams, Leila Berg, Nan Berger, Michael Duane, Alexander Sutherland Neill \& Robert Ollendorff, Los derechos de los niños, hacia la liberalización del niño, 119 (Julián Hall, comp., María Aurora Reyes de Baroco, trad., Editorial Extemporáneos, México, 1979).

27 Mónica González-Contró, Mauricio Padrón-Innamorato, Daniel Márquez-Gómez, Rosío Arroyo-Casanova \& Pastora Melgar-Manzanilla, Propuesta teórico-metodológica para la 
Esto debido a que, como se observó, las sociedades antiguas concebían al niño como propiedad de terceros, padres o comunidad política, y la infancia era considerada un asunto de derecho privado $^{28}$. Así mismo, la niñez continuaba siendo considerada por la ley como objeto o posesión de los progenitores y, por lo tanto, no había ningún interés en crear un cuerpo jurídico especializado para los niños. Al respecto, Pedro Nikken señala que después de que los niños sufrieron prácticas bárbaras y crueles generalizadas en todos los sectores sociales, se requerían un cambio de actitud y una visión más humanitaria hacia la niñez ${ }^{29}$. De esta forma, este proceso de reconocimiento fue lento y marchó paralelo a la superación de la barrera antes infranqueable entre lo público y lo privado en el ámbito familiar ${ }^{30}$.

Debido a esta situación, reformadores sociales, médicos, pedagogos, educadores, pediatras y asociaciones de protección a la infancia comenzaron a despertar interés en el tema y, en general, surgió la necesidad de internacionalizar políticas públicas a favor de la infancia ${ }^{31}$. De esta forma, durante este período se llevaron a cabo diversos congresos internacionales para discutir los problemas de los infantes, que posteriormente sirvieron para el surgimiento de organismos internacionales $\mathrm{y}$, mejor aún, instrumentos internacionales que brindaran protección a la niñez. Otra de las características relevantes de esta época es que los Estados debatieron sobre asuntos de carácter público, asumiendo responsabilidades compartidas en la protección y los cuidados de los menores de edad. En este sentido, los debates

armonización legislativa desde el enfoque de derechos de niñas, niños y adolescentes, 4 (Instituto de Investigaciones Jurídicas de la Universidad Nacional Autónoma de México, UNAM, México, 2012).

28 Rony Eulalio López-Contreras, Interés superior de los niños y niñas: definición y contenido, 13 Revista Latinoamericana de Ciencias Sociales, Niñez y Juventud, 1, 51-70, 54 (2015). Disponible en: http://revistaumanizales.cinde.org.co/index.php/Revista-Latinoamericana/article/ view/1635/532

29 Pedro Nikken, Los derechos del niño, de los ancianos y de la mujer: su protección internacional, 4 Revista IIDH/Instituto Interamericano de Derechos Humanos, 15-42, 26 (1986). Disponible en: http://www.iidh.ed.cr/IIDH/media/1609/revista-iidh4.pdf

30 José Manuel de Torres-Perea, Interés del menor y derecho de familia: una perspectiva multidisciplinar, 32 (Iustel, Madrid, 2009).

31 Paulí Dávila-Balsera \& Luis María Naya-Garmendia, comps., Derechos de la infancia y educación inclusiva en América Latina, 34 (Granica, Buenos Aires, 2011). 
se centraron en temas como la definición de niño, las formas de protegerlo y la intervención del Estado en relación con su protección $^{32}$.

En primer lugar, diversos Estados se reunieron para encontrar soluciones a los problemas de la desnutrición y las enfermedades de la infancia. Debido a ello, se llevaron a cabo tres importantes congresos internacionales, también llamados "Gotas de Leche" ${ }^{33}$. En el primero de ellos, que se celebró en París en 1905, se discutieron los temas de los depósitos y la distribución de leche relacionada con la visita médica. El segundo congreso se llevó a cabo en Bruselas en 1907 y tercero en Berlín en 1911, que ampliaron las discusiones a temas relacionados con la educación, la legislación para la protección de la infancia y la estadística sobre la mortalidad infantil ${ }^{34}$. Si bien es cierto que las discusiones en los congresos internacionales sobre la infancia giraban alrededor de dos polos, es decir, "uno jurídico y teórico y, otro más pragmático" 35 , la realidad es que estos congresos sirvieron de inspiración para poner en la agenda internacional la situación de la infancia para crear instrumentos internacionales.

Paralelamente, en este período, se crearon asociaciones internacionales, que trabajaban en el tema de la infancia y comenzaban a tener mayor relevancia y presencia en los foros internacionales, como la Asociación Internacional de Protección de la Infancia, la Unión Internacional para la Protección de la Infancia en la Primera Edad, la Unión Internacional de Salvación del Niño (actualmente, Save the Children) y la Liga de Sociedades de la Cruz Roja. Debido al interés y los objetivos de estas asociaciones a favor de la niñez, en 1923 promulgaron la primera Declaración Sistemática de los Derechos del Niño,

32 Paulí Dávila-Balsera \& Luis María Naya-Garmendia, comps., Derechos de la infancia y educación inclusiva en América Latina, 32 (Granica, Buenos Aires, 2011).

33 Algunos de los países con mayor presencia en los Congresos son: España, Francia, Alemania, Reino Unido, Italia, Argentina, Holanda y Suiza.

34 Catherine Rollet, La santé et la protection de l'enfant vues à travers les Congrès internationaux (1880-1920), 101 Annales de Démographie Historique, 1, 97-116, 104-106 (2001). Disponible en: https://www.cairn.info/revue-annales-de-demographie-historique-2001-1-page-97.htm

35 Catherine Rollet, La santé et la protection de l'enfant vues à travers les Congrès internationaux (1880-1920), 101 Annales de Démographie Historique, 1, 97-116 (2001). 
la cual fue redactada principalmente por la pedagoga británica Eglantyne $\mathrm{Jebb}^{36}$, quien defendió la relevancia de reconocer la protección de la niñez desde el ámbito internacional, entre otros aspectos.

Debido a la importancia internacional del tema, esta iniciativa fue rescatada y adoptada por la Liga de las Naciones, que la proclamó en una resolución con naturaleza jurídica de declaración y le dio la fuerza legal que requería su antecesora ${ }^{37}$.

Así en 1924 surgió la primera Declaración sobre Derechos de los Niños o Declaración de Ginebra, un breve texto de cinco puntos que recogía la demanda de unos deberes básicos que "los hombres y las mujeres de todas las naciones" declaraban y aceptaban como un deber "más allá y sobre toda consideración de raza, nacionalidad o credo" 38 .

Algunas de las obligaciones de este instrumento eran: dar a los niños los medios necesarios para su normal desarrollo, tanto material como espiritual; alimentar al infante hambriento; el deber de cuidado al menor de edad enfermo; ayudar al infante deficiente; recuperar al niño delincuente y recoger y socorrer al huérfano; el deber de que el infante sea el primero en recibir ayuda en tiempo de peligro; disponer de los medios que lo capaciten para llegar a ganarse la vida; el deber de ser protegido de cualquier explotación y; el deber ser educado en la conciencia de que sus talentos deben ser dedicados al servicio del prójimo ${ }^{39}$.

36 Eglantyne Jebb puso de manifiesto que las actuaciones de las personas e instituciones civiles deben ser una prioridad internacional para la protección de los derechos de los niños. Además de ser fundadora de la organización Save the Children Fund, fue pionera en poner en el centro de atención un catálogo internacional de derechos del niño y para considerar al niño como sujeto de derechos. Ambas iniciativas fueron rescatadas por la Convención sobre Derechos del Niño.

37 De acuerdo con Norberto Bobbio, las declaraciones, en particular la universal, son instrumentos cuyos principios tienen como destinatarios no solo los ciudadanos de un determinado Estado, sino toda la humanidad. Además, positivizan en el sentido de que ponen en marcha un proceso de concreción y garantía universal de los derechos.

38 Liga de las Naciones, Declaración sobre Derechos de los Niños o Declaración de Ginebra, 26 de septiembre de 1924. Disponible en: http://ojd.org.do/Normativas/Penal\%20NNA/Instrumentos \%20internacionales/Declaracion\%20de\%20Ginebra\%201924.pdf, http://www.humanium.org/ es/declaration-de-geneve-du-26-septembre-1924/

39 Ana Paz Garibo-Peyró, Los derechos de los niños: una fundamentación, 280 (Ministerio del Trabajo y Asuntos Sociales, Madrid, 2004). 
A pesar de este avance jurídico, esta Declaración no contenía de forma expresa derechos a favor de los menores de edad, sino más bien se refería a una serie de obligaciones de los adultos que eran responsables de los infantes. En otras palabras, este instrumento internacional contenía una serie de obligaciones de los adultos a favor de los niños, por lo que este hecho significaba que el niño era, todavía, considerado objeto de protección y no sujeto de derechos.

Para algunos autores, esta Declaración es sucinta, debido a una serie de derechos dentro de la dimensión protectora, como alimentos, cuidado, ayuda, acogida y socorro, educación y reinserción del niño delincuente, entre otros. Sin embargo, no reconocía el derecho de los niños a contar con progenitores ni tampoco reconocía el derecho a ser sujeto de derechos ${ }^{40}$. Por lo tanto, esta Declaración recibió diversas críticas tras no contar con garantías suficientes que protegieran los derechos civiles y políticos, derechos que son propios de los sujetos de derechos ${ }^{41}$.

A causa de los sucesos sociales que enfrentó la humanidad con dos grandes guerras mundiales durante el siglo XX, comenzaron a reconocerse los derechos humanos. Así, para algunos autores, este reconocimiento se debió a la despiadada y masiva destrucción de individuos y grupos en los Estados, y al desprecio que se evidenciaba por el ser humano y el agudo deterioro de las relaciones entre el Estado y el hombre. Estos factores ayudaron a que se intentara desde entonces elevar los derechos humanos a la categoría de normas internacionales y conseguir una cierta protección para estos derechos ${ }^{42}$.

En este orden de ideas, después de pasados los embates de la Segunda Guerra Mundial, en 1945 se creó la Organización de las Naciones Unidas $(\mathrm{ONU})^{43}$, cuyos objetivos eran: mantener

40 Paulí Dávila-Balsera \& Luis María Naya-Garmendia, La evolución de los derechos de la infancia: una visión internacional, 7 Revista Encounters on Education, 71-93, 78 (2006). Disponible en: http://ojs.library.queensu.ca/index.php/encounters/article/view/597/3498

41 Ana Paz Garibo-Peyró, Los derechos de los niños: una fundamentación, 201-203 (Ministerio del Trabajo y Asuntos Sociales, Madrid, 2004).

42 Karel Vasak, Las dimensiones internacionales de los derechos humanos, Vol. I, 50 (Hernán Sabaté y María José Rodellar, trads., Editorial Serbal, Barcelona, 1984).

43 Organización de las Naciones Unidas, Asamblea General, Carta de las Naciones Unidas, San 
la paz y la seguridad internacional en asuntos económicos, sociales, culturales y humanitarios, y el respeto de los derechos humanos y las libertades fundamentales.

Debido a lo anterior, se creó la Declaración Universal de los Derechos Humanos de $1948^{44}$, el cual es un instrumento internacional compuesto por 30 artículos. De acuerdo con René Cassin, miembro de la Comisión Redactora de la Declaración, esta cuenta con una clasificación respecto de los derechos contenidos en cuatro rubros: derechos personales; derechos que pertenecen al individuo en relación con el grupo social, libertades civiles; y los derechos políticos; y los derechos de naturaleza económica o social ${ }^{45}$.

En relación con nuestra materia, en el texto de este instrumento se reconocen algunos derechos de la niñez. El primero de ellos es el artículo 25 párrafo segundo, el cual señala explícitamente que los niños tienen el derecho a acceder a la protección social independiente. El otro artículo es el 16, el cual protege el derecho a la familia y, por último, el artículo 26, el cual reconoce el derecho a la educación. Aunque la naturaleza jurídica de la Declaración le quita la fuerza jurídica vinculante, algunos autores han defendido su obligatoriedad.

En este sentido, Eduardo Jiménez de Aréchaga ha señalado que la Declaración Universal de Derechos Humanos es un instrumento normativo que establece por lo menos algunas obligaciones legales para los Estados miembros de la ONU, tras ser considerada la interpretación autorizada de las obligaciones en materia de derechos humanos contenidas en la Carta de la ONU y, por lo tanto, este hecho lo hace ser un instrumento obligatorio y vinculante ${ }^{46}$. Por su parte, Héctor Gros-Espiell

Francisco, 26 de junio de 1945. Disponible en: http://www.un.org/es/charter-united-nations/ index.html

44 Organización de las Naciones Unidas, Asamblea General, Declaración Universal de los Derechos Humanos, adoptada en la Resolución 217 A (III), 10 de diciembre de 1948. Disponible en: http://www.un.org/es/universal-declaration-human-rights/

45 Cristóbal R. Garro, Declaración Universal de Derechos Humanos, Abriendo surcos, 2 (Depalma, Buenos Aires, 1985).

46 De acuerdo con este autor, el alcance jurídico de la Carta de Naciones Unidas en materia de derechos y libertades fundamentales aludidos en ella se extiende a la Declaración de 1948, la 
ha sostenido que la Declaración ha dejado así de tener solo un valor moral para transformarse en un documento del que se derivan para los Estados deberes y obligaciones concretos ${ }^{47}$. Además, este autor ha afirmado que el deber de respetar los derechos del ser humano constituye una norma imperativa de derecho internacional general, un caso de ius cogens, quizás el más característico de nuestra época, con todas las consecuencias de esta afirmación, cuyo respeto y vigencia se vinculan con la idea de "orden público internacional", lo que implica también efectos de obvia importancia ${ }^{48}$.

Siguiendo con el tema del capítulo, en 1959, el Consejo Económico y Social de Naciones Unidas (ECOSOC) elaboró un Decálogo de los Derechos del Niño, en el que por primera vez, la Asamblea General aprobó y proclamó la Declaración de los Derechos del Niño ${ }^{49}$. Este documento contempla una serie de derechos y libertades a favor de la niñez; de igual forma, revoluciona el contenido de la norma al contemplar en su artículo 1, el principio de la no discriminación y en el artículo 2, el principio del interés superior del niño. Sin embargo, para algunos autores, este último principio careció de todo sentido, debido a la amplitud con que quedó plasmado ${ }^{50}$.

Debido a la presión internacional en defensa de los intereses de la niñez, Naciones Unidas declaró en 1979 el Año Internacional del Niño, con la intención de visualizar su importancia en las discusiones que lo afectaban. Esto debido a que la materia a

cual tiene su fundamento en el valor práctico esencial de la última, ya que radica en resolver a cuáles derechos humanos fundamentales, sin enumerarlos, se refiere la Carta originaria. Eduardo Jiménez de Aréchaga, Derecho constitucional de las Naciones Unidas: comentario teórico-práctico de la Carta, 439-442 (Escuela de Funcionarios Internacionales, Madrid, 1958).

47 Héctor Gros-Espiell, Los derechos humanos y el derecho internacional, 1968-1977, 10 Jurídica, Anuario del Departamento de Derecho de la Universidad Iberoamericana, tomo II, 152-166, 157 (1978). Disponible en: http://historico.juridicas.unam.mx/publica/librev/rev/jurid/cont/10/ pr/pr33.pdf

48 Ibid.

49 Organización de las Naciones Unidas, Asamblea General, Declaración de los Derechos del Niño, Resolución 1386 (XIV), 14 UN GAOR Supp. (No. 16), 19, ONU Doc. A/4354 (1959), 20 de noviembre de 1959. Disponible en: https://www.oas.org/dil/esp/Declaraci\%C3\%B3n\%20 de $\% 2010$ \% $\% 20$ Derechos\%20del $\% 20 \mathrm{Ni} \% \mathrm{C} 3 \%$ Blo\%20Republica\%20Dominicana.pdf

50 Tilde Longobardo, La Convenzione internazionale sui Diritti del Fanciullo, New York, 20 novembre 1989, 1 Il Diritto di Famiglia e delle Persone, 370-427, 386-387 (1991). 
tratar es de un alto contenido social y cultural, el esfuerzo por alcanzar un consenso sobre los derechos que debían incluir, lo cual continuó por una década ${ }^{51}$.

La internacionalización de estos derechos trajo una serie de beneficios a favor de la infancia. En primer lugar, la comunidad internacional organizada le dio la valoración propia del derecho internacional. Esto significa que esta rama del derecho reconoció la importancia de estos derechos al otorgarles el valor internacional que merecen o, en otros términos, porque son un ideal al que le debe prestar acogida para cooperar en su realización, y para brindarle protección con sus mecanismos propios, en refuerzo de su posición sociológica ${ }^{52}$.

Otro de los beneficios que provocó la internacionalización de los derechos de la niñez es que pueden ser garantizados mediante instrumentos internacionales $y$, esto repercute en que se haga más difícil su transgresión o derogación ${ }^{53}$. Aunque la obligación de estas normas internacionales dependa de la ratificación por los Estados parte, su protección y observancia están protegidas en el ámbito internacional, de forma que la preeminencia del derecho que nos ocupa radica en que los Estados en pleno uso de sus facultades soberanas consientan en ratificar y obligarse a la norma internacional, y a brindarle el nivel jerárquico de acuerdo a su norma jurídica interna. Sobre este asunto, Claudio Grossman explica que las normas internacionales han creado un nivel de legitimación más allá de las fronteras nacionales para aquellos que apoyan el sistema democrático de gobierno ${ }^{54}$. Además, el mismo autor afirma que la existencia de un sistema internacional de derechos humanos permite alcanzar un doble

51 Fondo de Naciones Unidas para la Infancia, UNICEF, Estado mundial de la infancia: Edición Especial. Conmemoración de los 20 años de la Convención sobre los Derechos del Niño, 5 (UNICEF, Nueva York, 2009). Disponible en: https://www.unicef.org/spanish/publications/ files/SOWC_Spec._Ed._CRC_Main_Report_SP_1201009.pdf

52 Germán J. Bidart-Campos, Teoría general de $\bar{l}$ os $\bar{d}$ erechos humanos, 41 (Astrea, Buenos Aires, 1991).

53 Edmundo Vargas-Carreño, Derecho internacional público: de acuerdo a las normas y prácticas que rigen en el siglo XXI, 519 (Editorial Jurídica de Chile, Santiago, 2007).

54 Claudio Grossman, Reflexiones sobre el sistema interamericano de protección y promoción de los derechos humanos, en La Corte y el Sistema Interamericano de Derechos Humanos, 246 (Rafael Nieto-Navia, ed., Corte Interamericana de Derechos Humanos, San José, 1997). 
objetivo: por una parte, puede contribuir a evitar el deterioro de sociedades democráticas, lo que permite la intervención de la comunidad hemisférica antes de que se produzca una situación de polarización extrema con probabilidades de salida de fuerza ${ }^{55}$.

Otra ventaja de la internacionalización de los derechos de la niñez es que su contenido y protección adoptaron carácter universal. Es decir, los derechos de la infancia adoptaron un uso no diferenciado entre personas, ya que sus destinatarios fueron tomados en cuenta como seres humanos, sin restricción de ninguna especie de carácter temporal, personal o espacial. Sobre este asunto, Pedro Nikken dice que la universalidad alude a la titularidad que tienen todas las personas con respecto a los derechos humanos, independientemente de regímenes políticos, sociales y culturales ${ }^{56}$.

Desde esta perspectiva, podemos aseverar que los derechos de niños reconocidos como universales tienen la característica adicional de ser derechos de cumplimiento obligatorio sin distinción alguna, siempre y cuando el Estado parte los haya ratificado. En este sentido, Joel Feinberg ha manifestado que los derechos obligatorios son obligaciones contempladas desde un punto de vista positivo; se trata de deberes cuyo cumplimiento es especialmente ventajoso para la comunidad y para el titular ${ }^{57}$. En este sentido, estos derechos reconocen al titular la facultad para no renunciar a su ejercicio. De esta forma, podemos decir que son derechos que no se pueden desprender de ellos, ni se pueden renunciar voluntariamente.

Otro beneficio de la internacionalización de los derechos de la niñez es que los niños adquieren legitimidad activa para denunciar abusos y transgresiones de sus derechos ante los órganos internacionales y/o tribunales internacionales, ya sea

55 Ibid.

56 Pedro Nikken, El concepto de derechos humanos, en Estudios básicos de derechos humanos, tomo I, 15-38, 22 (Instituto Interamericano de Derechos Humanos, IIDH, San José de Costa Rica, 1994). Disponible en: http://www.iidh.ed.cr/IIDH/media/2250/estudios-basicos-01-1994. pdf

57 Joel Feinberg, Rights, Justice and the Bounds of Liberty: Essays in Social Philosophy, 235 (Princeton University Press, Princeton, New Jersey, 1980). 
mediante mecanismos individuales de denuncia o por soluciones judiciales. Cabe señalar que esta facultad está supeditada a que el Estado haya ratificado los instrumentos internacionales en la materia, en particular el Protocolo Facultativo de la Convención sobre los Derechos de los Niños. A pesar de que se requiera su ratificación para ejercitar este derecho, la importancia de este radica en que cambia la perspectiva jurídica tradicional de que los menores de edad sean considerados incapaces para exigir sus derechos, es decir, titular de los mismos y, por lo tanto, en caso de transgresión a sus derechos humanos, con esta visión, no habría impedimento alguno para ejercer personalmente una denuncia por violación de derechos humanos ante tribunales internacionales ${ }^{58}$. Incluso ante organismos, tal como lo establece el artículo 5 del Protocolo Facultativo de la Convención sobre los Derechos de $\operatorname{los} \mathrm{Niños}^{59}$, que señala que cualquier persona, incluidos los infantes, puede presentar denuncias individuales al Comité de Derechos del Niño (en adelante, Comité DN) en caso de sufrir alguna vulneración de sus derechos; sin embargo, uno de los requisitos para ejercer este derecho es que se hayan agotado los recursos internos. Sobre este asunto, Mónica González-Contró aclara que mientras alcanzan la mayoría de edad, los "menores de edad" solo pueden ser titulares de derechos, pero no pueden defenderse directamente ${ }^{60}$.

A pesar de esta postura, la protección de estos derechos depende en gran medida tanto de la existencia de órganos que pue-

58 Organización de Estados Americanos, OEA, Convención Americana sobre Derechos Humanos, San José, Costa Rica, 7 al 22 de noviembre de 1969, artículos 46 y 47. Disponible en: https:// www.oas.org/dil/esp/tratados_b-32_convencion_americana_sobre_derechos_humanos.htm. Organización de Estados Americanos, OEA, Reglamento de la Comisión Interamericana de Derechos Humanos, aprobado por la Comisión en su $137^{\circ}$ período ordinario de sesiones, 28 de octubre al 13 de noviembre de 2009, artículos 28 a 34. Disponible en: http://www.oas.org/ es/cidh/mandato/Basicos/reglamentoCIDH.asp

59 Organización de las Naciones Unidas, Asamblea General, Comité sobre Derechos del Niño, Protocolo facultativo de la Convención sobre los Derechos del Niño relativo a un procedimiento de comunicaciones, Asamblea General, Resolución A/Res/66/138 (2011). Disponible en: http:// www.acnur.org/t3/fileadmin/Documentos/Proteccion/Buenas_Practicas/9532.pdf?view=1

60 Mónica González-Contró, Mauricio Padrón-Innamorato, Daniel Márquez-Gómez, Rosío Arroyo-Casanova \& Pastora Melgar-Manzanilla, Propuesta teórico-metodológica para la armonización legislativa desde el enfoque de derechos de niñas, niños y adolescentes, 14 (Instituto de Investigaciones Jurídicas de la Universidad Nacional Autónoma de México, UNAM, México, 2012). 
den promover la defensa de tales derechos como de mecanismos de control y vigilancia de los derechos protegidos ${ }^{61}$. Ahora bien, la protección de estos derechos no solo requiere que el peticionario denuncie las violaciones ante órganos internacionales, sino que hay otras posibilidades que ofrecen sistemas de protección. Por ejemplo: mediante informes periódicos que realizan ciertos organismos sobre la situación de derechos de la infancia, o bien, sobre una situación de un derecho determinado. Estos informes ayudan a visualizar las medidas adoptadas por el Estado para dar mayor efectividad a los derechos objeto de protección y a disminuir la brecha que podría producirse entre la obligación a la que se ha comprometido un Estado parte con lo que efectivamente está realizando. También es posible discutir y adoptar resoluciones de organismos especializados sobre la niñez, como aquellas observaciones realizadas por el Comité de DN y, por último, los resultados de una observación in loco ${ }^{62}$.

\section{Convención SOBRe Derechos DEl NiÑo}

Tomando en consideración la evolución histórica de los derechos de la infancia, la aprobación en 1989 de la Convención sobre Derechos de los Niños ${ }^{63}$ implicó un paso importante sobre el tratamiento jurídico hacia la infancia, pues reconoció importantes derechos a favor de este grupo social. Es decir, se incorporaron derechos civiles y políticos a favor de este grupo y, finalmente se les reconoció como sujetos de derechos, lo cual

61 Edmundo Vargas-Carreño, Derecho internacional público: de acuerdo a las normas y prácticas que rigen en el siglo XXI, 527 (Editorial Jurídica de Chile, Santiago, 2007).

62 Las observaciones in loco tienen por objeto investigar y verificar hechos en el país en el que se ha incurrido en violaciones a los derechos humanos, incluidos los derechos de los niños. De igual forma, implica la oportunidad para dialogar con las autoridades a fin de prevenir y corregir situaciones que afecten la vigencia de los derechos humanos. Por lo general, los resultados de una observación in loco se consignan en un informe, aunque este también puede redactarse sin que se haya realizado la observación previa. Los informes pueden referirse a la situación en general de derechos humanos de un determinado Estado o a una situación particular relativa a la vigencia de los derechos humanos.

63 Organización de las Naciones Unidas, Asamblea General, Convención sobre Derechos del Niño, adoptada y abierta a la firma y ratificación por la Asamblea General en su Resolución 44/25, 20 de noviembre de 1989, entrada en vigor 2 de septiembre de 1990. Disponible en: http://www. hchr.org.co/documentoseinformes/documentos/html/pactos/conv_derechos_nino.html 
rompió uno de los más lesivos lastres que enfrentó este grupo. Por lo tanto, la adopción de este instrumento internacional significó un hecho histórico de gran valor al ser un instrumento jurídico vinculante que ha sido ratificado por casi todos los Estados del mundo, excepto Estados Unidos, que ha tenido una resistencia a este por su falta de compromiso a reconocer derechos que van más allá de su legislación interna ${ }^{64}$. Por ejemplo, uno de los principales argumentos de ese país es que la figura jurídica de la pena de muerte para los menores de edad sigue estando vigente en varios estados de la Unión y, por lo tanto, sería contraria a la naturaleza y sentido de la Convención DN.

Por otro lado, la Convención DN también introduce por primera vez derechos y principios específicos a favor de la infancia, como el interés superior de la niñez como un principio trascendental, junto con la autonomía progresiva de los niños y, como mencionamos anteriormente, el reconocimiento de estos como sujetos titulares de derechos humanos ${ }^{65}$. También reconoce un catálogo de derechos específicos que ya habían sido reconocidos por otros instrumentos internacionales de carácter general, pero que al incorporarlos en la Convención refuerzan la idea de que también son aplicables a la infancia, como el derecho a recibir asilo, el derecho a la vida y el derecho a la educación, entre otros.

Para algunos autores, este nuevo paradigma jurídico significó contar con una nueva rama del derecho que brinda una mayor protección reforzada. En este sentido, Miguel Cillero-Bruñol señaló que la Convención no es meramente una reafirmación de los derechos del niño como persona humana, sino una especificación de estos derechos para las particulares circunstancias de vida de la infancia y de un conjunto de principios que regulan la protección conjunta de los derechos de este grupo y los adultos,

64 Organización de Naciones Unidas, Centro de Noticias, Con Somalia, 196 países han ratificado ya la Convención sobre los Derechos del Niño (1 de octubre de 2015). Disponible en: http:// www.un.org/spanish/News/story.asp?NewsID=33493\#.VusWefnhCUk, http://www.un.org/ spanish/News/story.asp?NewsID=33493\#.WRiyP2jhA65

65 El reconocimiento de los infantes como titulares de derechos significa reconocerlos como personas con cualidades y necesidades únicas. Además, este concepto ha evolucionado conjuntamente con el desarrollo progresivo de los derechos de la niñez. 
y sus derechos y deberes recíprocos ${ }^{66}$. Este proceso de distinción de la materia en relación con los derechos humanos es a lo que Norberto Bobbio se refería como el proceso de especificación de los derechos, el cual "consiste en el paso gradual pero cada vez más acentuado hacia una ulterior determinación de los sujetos titulares de los mismos"67. Así, este proceso ha sobrevenido respecto a los sujetos, aquello que ocurrió desde el inicio respecto a la idea abstracta de libertad que se fue determinando en libertades concretas y singulares ${ }^{68}$. De esta forma, la especificación de los derechos se ha producido bien respecto al género, bien respecto a las distintas fases de la vida, bien teniendo en cuenta la diferencia entre estado normal y estado excepcional en la existencia humana. Así, pueden citarse, en este sentido, los textos que hacen referencia a los derechos del niño, entre otros ${ }^{69}$.

Por su parte, Gregorio Peces-Barba Martínez puntualiza que el proceso de especificación en relación con los titulares parte de la idea de vincular los derechos con ciertas circunstancias de las personas concretas, ya sea por su condición social, cultural, física (como sería el caso de los menores de edad) o por su situación en determinadas relaciones sociales. Así, para este autor, la evolución de los derechos humanos ha pasado por diferentes etapas: positivización, generalización, internacionalización y especificación ${ }^{70}$. De esta suerte, el proceso de especificación se relaciona con los derechos anteriormente reconocidos por los instrumentos internacionales universales, pero detalla ciertas particularidades para grupos concretos, como es el caso de las niñas y niños.

66 Miguel Cillero-Bruñol, El interés superior del niño en el marco de la Convención Internacional sobre los Derechos del Niño, en Infancia, Ley y Democracia en América Latina, 69-85 (Emilio García-Méndez \& Mary Belloff, comps., Ediciones Temis, Ediciones Desalma, Bogotá, Buenos Aires, 1998).

67 Norberto Bobbio, El tiempo de los derechos, 154 (Editorial Sistema, Madrid, 1991).

68 Norberto Bobbio, El tiempo de los derechos, 110 (Editorial Sistema, Madrid, 1991).

69 Norberto Bobbio, El tiempo de los derechos, 109-110 (Editorial Sistema, Madrid, 1991).

70 Gregorio Peces-Barba Martínez, Curso de derechos fundamentales: teoría general, 154 (Universidad Carlos III de Madrid, Boletín Oficial del Estado, Madrid, 1995). 


\section{CORPUS JURIS EN MATERIA DE DERECHO DE LA INFANCIA}

La influencia del movimiento contemporáneo en beneficio de la protección internacional de los derechos humanos desencadenó el surgimiento del derecho de la niñez, producto de la evolución histórica del reconocimiento de estos derechos. Además, el desarrollo de los derechos de los niños parece formar parte del fenómeno de expansión de los derechos humanos y algunos autores llaman a este proceso "especificación"”1. La especificación de este derecho es incuestionable y hace importantes aportes al derecho internacional público que se reflejan en la interpretación y aplicación de los instrumentos internacionales en la materia.

Así, la existencia de un Corpus Juris en materia de niñez significa el reconocimiento de la existencia de un conjunto de normas fundamentales que están vinculadas con el fin de garantizar los derechos humanos de niñas y niños. De esta manera, los derechos de la niñez no se limitan al texto de la $\mathrm{CDN}^{72}$, sino que incluyen el marco jurídico internacional aplicable a la protección de la niñez y que conformarían en su conjunto el Corpus Juris de los Derechos de la Niñez.

Algunos de los instrumentos internacionales relacionados con los derechos de la niñez son: el Protocolo Facultativo de la Convención sobre los Derechos del Niño relativo a la Participación de Niños en Conflictos Armados ${ }^{73}$, el Protocolo Facultativo de la Convención sobre los Derechos del Niño relativo a la Venta de Niños, la Prostitución Infantil y la Utilización de Niños en la Pornografía ${ }^{74}$, el Convenio 138 sobre la edad mínima

71 Mónica González-Contró, Derecho de familia en México, 56 (Instituto de Investigaciones Jurídicas de la Universidad Nacional Autónoma de México, UNAM, México, 2010).

72 Organización de las Naciones Unidas, Asamblea General, Convención sobre Derechos del Niño, adoptada y abierta a la firma y ratificación por la Asamblea General en su Resolución 44/25, 20 de noviembre de 1989, entrada en vigor 2 de septiembre de 1990. Disponible en: http://www. hchr.org.co/documentoseinformes/documentos/html/pactos/conv_derechos_nino.html

73 Organización de las Naciones Unidas, Asamblea General, Protocolo Facultativo de la Convención sobre los Derechos del Niño relativo a la Participación de Niños en Conflictos Armados, Resolución A/RES/54/263, New York, 25 de mayo de 2000. Disponible en: http://www.un.org/ es/comun/docs/?symbol=A/RES/54/263

74 Organización de las Naciones Unidas, Asamblea General, Protocolo Facultativo de la Convención sobre los Derechos del Niño relativo a la Venta de Niños, la Prostitución Infantil y la 
de admisión al empleo ${ }^{75}$, el Convenio 182 sobre la prohibición de las peores formas de trabajo infantil y la acción inmediata para su eliminación ${ }^{76}$ y el Convenio de La Haya relativo a la Protección del Niño y la Cooperación en Materia de Adopción Internacional ${ }^{77}$.

Así mismo, hay otros textos internacionales de alcance mundial sobre cuestiones específicas relacionadas con la niñez, como las Reglas de Beijing, $1985^{78}$, las Directrices de Riad, $1990^{79}$, las Reglas de Tokio, $1990^{80} \mathrm{y}$ las Recomendaciones sobre el Consentimiento para el Matrimonio, la Edad Mínima para Contraer Matrimonio y Registro de los Matrimonios ${ }^{81}$.

La Corte Interamericana ha estipulado que el corpus juris en materia de niñez sirve para fijar el contenido y los alcances del artículo 19 de la Convención Americana y es el resultado de la evolución del derecho internacional de los derechos humanos

Utilización de Niños en la Pornografía, Resolución A/RES/54/263, New York, 25 de mayo de 2000. Disponible en: http://www.ohchr.org/SP/ProfessionalInterest/Pages/OPSCCRC.aspx

75 Organización Internacional del Trabajo, OIT, Convenio C138, Convenio sobre la edad mínima de admisión al empleo, Ginebra, 26 de junio de 1973. Disponible en: http://www.ilo.org/dyn/ normlex/es/f?p=NORMLEXPUB:12100:0::NO::P12100_ILO_CODE:C138

76 Organización Internacional del Trabajo, OIT, Convenio $\bar{C} 182, \bar{C}$ Convenio sobre la prohibición de las peores formas de trabajo infantil y la acción inmediata para su eliminación, Ginebra, 17 de junio de 1999. Disponible en: http://www.ilo.org/dyn/normlex/es/f?p=1000:12100:0::NO::P12100_ ILO_CODE:C182

77 Conferencia de La Haya de Derecho Internacional Privado, Convenio relativo a la Protección del Niño y la Cooperación en Materia de Adopción Internacional, La Haya, 29 de mayo de 1993. Disponible en: https://www.hcch.net/es/instruments/conventions/full-text/?cid=69

78 Organización de las Naciones Unidas, Asamblea General, Reglas Mínimas de las Naciones Unidas para la Administración de Justicia de Menores, A.G. res. 40/33, anexo, 40 U.N. GAOR Supp. (No. 53) p. 207, ONU Doc. A/40/53 (1985) (Directrices de Beijing, 1985), Beijing, 29 de noviembre de 1985. Disponible en: https://www.unicef.org/panama/spanish/7972.htm

79 Organización de las Naciones Unidas, Asamblea General, Directrices de las Naciones Unidas para la Prevención de la Delincuencia Infantil (Directrices de Riad, 1990), Resolución 45/112, 14 de diciembre de 1990. Disponible en: http://www.un.org/es/comun/docs/?symbol=\%20A/ RES/45/112\&Lang $=\mathrm{S}$

80 Organización de las Naciones Unidas, Asamblea General, Reglas Mínimas de las Naciones Unidas para la Protección de los Menores Privados de la Libertad, Resolución 45/113 (Reglas de Tokio, 1990), Tokio, 14 de diciembre de 1990. Disponible en: http://www.un.org/es/comun/ docs $/$ ?symbol $=\% 20 \mathrm{~A} / \mathrm{RES} / 45 / 113 \&$ Lang $=\mathrm{S}$

81 Organización de las Naciones Unidas, Asamblea General, Convención sobre el consentimiento para el matrimonio, la edad mínima para contraer matrimonio y el registro de los matrimonios, Resolución 1763 A (XVII), 7 de noviembre de 1962. Disponible en: http://www.ohchr.org/SP/ ProfessionalInterest/Pages/MinimumAgeForMarriage.aspx. Organización de las Naciones Unidas, Asamblea General, Recomendaciones sobre el Consentimiento para el Matrimonio, la Edad Mínima para Contraer Matrimonio y Registro de los Matrimonios, Resolución 2018 (XX) de la Asamblea General, 1 de noviembre de 1965. Disponible en: http://www.ohchr.org/ SP/ProfessionalInterest/Pages/RecommendationOnConsentToMarriage.aspx 
en materia de niñez que tiene como eje el reconocimiento de los niños como sujetos de derechos ${ }^{82}$. Esto debido a que tanto la Convención Americana como la CDN forman parte de un muy comprensivo corpus juris internacional de protección de los niños que debe servir a esta Corte para fijar el contenido y los alcances de la disposición general definida en el artículo 19 de la Convención Americana ${ }^{83}$.

\section{COMPATIBILIDAD DEL DERECHO INTERNACIONAL} DE LOS DERECHOS A FAVOR DE LA NIÑEZ

Después de observar que hay un Corpus Juris en materia de niñez, surge la interrogante sobre si este solo aplica a las normas jurídicas que integran el derecho internacional de los derechos humanos, o bien, también implica que este derecho se amplía a la esfera de competencia de otras ramas del derecho internacional público, como el derecho internacional humanitario y el derecho internacional de los refugiados.

Así, la convergencia del derecho de la niñez y otras ramas del derecho internacional público reside en que todas ellas se complementan y ninguna se contrapone; de tal forma que la interrelación de esta área específica con el derecho internacional de los derechos humanos y otras ramas deriva en el reconocimiento del carácter especial de los tratados de protección de los derechos humanos. Así, la implementación de tales instrumentos internacionales detecta el papel preeminente ejercido por el elemento de la interpretación en la evolución del derecho internacional de los derechos humanos, el cual ha asegurado que aquellos instrumentos se mantengan vivos $^{84}$.

82 Comisión Interamericana de Derechos Humanos y Relatoría sobre Derechos de la Niñez, Justicia juvenil y derechos humanos en las Américas, 5, 6 (OEA/Ser.L/V/II, Doc. 78, 2011). Disponible en: https://www.oas.org/es/cidh/infancia/docs/pdf/justiciajuvenil.pdf

83 Corte Interamericana de Derechos Humanos, Corte IDH, Opinión Consultiva OC-17/02, Serie A 17, Condición jurídica y derechos humanos del niño, 28 de agosto de 2002, párrs. 37 y 53. Disponible en: http://www.corteidh.or.cr/docs/opiniones/seriea_17_esp.pdf

84 Antônio Augusto Cançado-Trindade, El derecho internacional de los derechos humanos en el siglo XXI, 224-225 ( $2^{\mathrm{a}}$ ed., Editorial Jurídica de Chile, Santiago, 2001). 
Por ejemplo, el Tribunal Europeo de Derechos Humanos ha preceptuado que la interpretación evolutiva no se limita a las normas sustantivas de la Convención Europea de Derechos Humanos, sino que se extiende igualmente a disposiciones operativas, como tratados internacionales en materias específicas como los derechos de la niñez ${ }^{85}$.

La doctrina, por su parte, ha sostenido que los derechos que inciden en la protección de la infancia no deben ser examinados ni aplicados aisladamente sino insertos en el esquema internacional de la protección de la niñez, que a partir de la Convención sobre los Derechos de los Niños de 1989 se ha construido por los sucesivos Convenios que afectan su protección ${ }^{86}$.

De esta forma, para interpretar las obligaciones del Estado en relación con los infantes, además de las disposiciones de la CDN, se considera importante acudir a otros instrumentos internacionales más específicos. En este sentido, las aproximaciones entre los regímenes complementarios de protección, entre el derecho internacional de los derechos humanos, el derecho internacional de los refugiados, el derecho internacional humanitario y el derecho internacional de los derechos del niño permiten complementar soluciones eficaces a problemas específicos que requieren la intervención de estos. Este argumento tiene fundamento en que conforme al derecho internacional público, un tratado sobre derechos de los niños y niñas debe seguir los criterios generales de interpretación señalados en la Convención de Viena sobre el derecho de los tratados. Es decir, que de acuerdo al artículo 31 de la Convención de Viena ${ }^{87}$ se prevé que, de manera subsidiaria a los criterios de la buena fe, el sentido corriente y el objeto

85 European Court of Human Rights, ECHR, Case of Titina Loizidou v. Turkey, 15318/89, Preliminary Objections, Judgment, 23 February 1995, par. 71. Disponible en: http://www. refworld.org/docid/402a07c94.html

86 Sandra García-Cano, Protección del menor y cooperación internacional entre autoridades, 62-63 (Colex, Madrid, 2003).

87 Artículo 31.1. Un tratado deberá interpretarse de buena fe conforme al sentido corriente que haya de atribuirse a los términos del tratado en el contexto de estos y teniendo en cuenta su objeto y fin. Organización de las Naciones Unidas, Asamblea General, Convención de Viena sobre el derecho de los tratados, Viena, 23 de mayo de 1969, artículo 31.1. Disponible en: http://www.oas.org/xxxivga/spanish/reference_docs/convencion_viena.pdf, http://legal.un.org/ diplomaticconferences/lawoftreaties-1969/docs/english/confdocs/a_conf_39_27.pdf 
y fin del tratado, se podrá recurrir a la interpretación de otros tratados internacionales afines a la materia para determinar el sentido del texto del tratado ${ }^{88}$.

Además, en muchos de los casos se requiere el perfeccionamiento de conocimientos técnicos o jurídicos especializados para el fortalecimiento de la protección internacional de la niñez en cualquiera de las situaciones o circunstancias específicas. Así, la sectorización del derecho internacional aporta la ventaja de contribuir al enriquecimiento y renovación del derecho internacional en la medida en que este se impregne con nuevos conceptos, normas, principios y valores provenientes de los sectores especializados ${ }^{89}$.

Así, los derechos de los niños están relacionados con el derecho internacional de los derechos humanos, el derecho internacional humanitario y el derecho internacional de los refugiados. El primero de ellos reconoce los estándares incorporados en los tratados y declaraciones internacionales en derechos humanos $\mathrm{y}$, como tales, se aplican en principio tanto en tiempos de guerra como en tiempos de paz. En cambio, el derecho internacional humanitario se aplica únicamente en caso de conflictos armados. Por último, el derecho internacional de los refugiados se aplica únicamente para las personas reconocidas como refugiados $\mathrm{y}$, también, para aquellas que buscan protección internacional.

Cabe señalar que actualmente hay dos teorías que señalan la relación entre estas tres ramas del derecho internacional público. Es decir, por un lado, tenemos la teoría clásica de la división y por otro lado, la teoría de la complementariedad.

La primera teoría afirma que estas tres ramas del derecho internacional público son diferentes e independientes, debido a sus orígenes históricos y por las personas a quienes va dirigida su aplicación ${ }^{90}$. Sobre el primero subraya que el derecho inter-

88 Elizabeth Salmón, Introducción al derecho internacional humanitario, 44 (Comité Internacional de la Cruz Roja, CICR, Lima, 2004). Disponible en: http://idehpucp.pucp.edu.pe/images/ publicaciones/introduccion_al_derecho_internacional_humanitario.pdf

89 Rosa Riquelme-Cortado, Derecho internacional: entre un orden global y fragmentado, 310-311 (Editorial Biblioteca Nueva, Madrid, 2005).

90 Antonio Gómez-Robledo, Fundadores del derecho internacional. Vitoria, Gentili, Suárez, 
nacional de los derechos humanos surge a partir de la Segunda Guerra Mundial mientras que el derecho internacional humanitario surgió antes que este, estaba contemplado primero en la costumbre internacional y posteriormente fue recogido por el Convenio de Ginebra de $1864^{91}$. Por otro lado, el derecho internacional de los refugiados surgió a partir de la Convención de 1951 sobre el Estatuto de los Refugiados ${ }^{92}$.

Sobre hacia quiénes va dirigido, esta teoría hace hincapié en que en el caso del derecho internacional de los refugiados se establecen derechos humanos mínimos hacia aquellas personas que salen de su país de origen, mientras que el derecho internacional humanitario se aplica para proteger a aquellas personas víctimas de los conflictos armados, y el derecho internacional de los derechos humanos a todas las personas de los Estados que han ratificado los instrumentos internacionales en esta materia ${ }^{93}$. Debido a lo anterior, esta teoría no admite interacción normativa entre estas tres ramas y, por lo tanto, deja afuera la complementariedad entre ellas.

Contrario a esta teoría, según una corriente doctrinaria más reciente, las tres áreas del derecho internacional están estrechamente relacionadas entre sí debido a que la prioridad

Grocio, 35-43 (Universidad Nacional Autónoma de México, UNAM, Instituto de Investigaciones Jurídicas, IIJ, México, 1992). Disponible en: https://biblio.juridicas.unam.mx/bjv/ detalle-libro/383-fundadores-del-derecho-internacional-vitoria-gentili-suarez-grocio

91 Consejo Federal suizo, Convenio de Ginebra, 22 de agosto de 1864 para el mejoramiento de la suerte de los militares heridos en los ejércitos en campaña. Disponible en: https://www.icrc. $\mathrm{org} / \mathrm{spa} /$ resources/documents/treaty/treaty-1864-geneva-convention-1.htm

92 Pedro Frutos, Compendio de derecho internacional público, 14 (Biblioteca Jurídica Argentina, Buenos Aires, 1932). Organización de las Naciones Unidas, Asamblea General, Convención sobre el Estatuto de los Refugiados, adoptada en Ginebra, Suiza, el 28 de julio de 1951 por la Conferencia de Plenipotenciarios sobre el Estatuto de los Refugiados y de los Apátridas (Naciones Unidas), convocada por la Asamblea General en su Resolución 429 (V), 14 de diciembre de 1950. Disponible en: http://www.acnur.org/fileadmin/scripts/doc.php?file=fileadmin/ Documentos/BDL/2001/0005

93 Uno de los principales propulsores de esta diferenciación fue Hugo Grocio. Debido a ello, el sistema actual del derecho internacional toma en cuenta lo anotado por Grocio en sus diversas obras y establece la división del sistema internacional en dos subsistemas: el derecho de paz y el derecho de guerra. El primero protege a los Estados contra el aniquilamiento, el sometimiento y la mutilación del territorio, así como a los individuos contra la destrucción deliberada y organizada en masa de vida y bienes. El derecho de guerra, en cambio, protege al hombre contra los sufrimientos y destrozos gratuitos. Hugo Grocio, Del derecho de la guerra y de la paz (Jaime Torrubiano-Ripoll, trad., Editorial Reus, Madrid, 1925). Disponible en: http://fama2. us.es/fde/ocr/2010/delDerechoDeLaGuerraYDeLaPazT1.pdf 
de cada una de ellas es el individuo y, por lo tanto, todas ellas son complementarias ${ }^{94}$. En este sentido, Christophe Swinarski conceptúa que entre estas ramas del derecho internacional público hay una complementariedad, es decir, son ramas del derecho diferentes, pero estrechamente unidas, complementarias, que tienden a proteger en diferentes procedimientos y con la actuación de diferentes órganos, a la persona humana ${ }^{95}$. En el mismo sentido, Albert Galinsoga-Jordà dice que hay una relación de complementariedad en cuanto al ámbito normativo $\mathrm{y}$, en ocasiones, un funcionamiento subsidiario entre el derecho internacional humanitario y el de los refugiados respecto de los derechos humanos, por lo tanto, en su ámbito de aplicación, el derecho de los refugiados y el humanitario funcionan como lex specialis. Este mismo autor, también, manifiesta que entre las tres ramas del derecho internacional público pueden coincidir en cuanto a sus contenidos. Por otro lado, es posible evidenciar una relación de subsidiaridad entre el derecho internacional de los refugiados y el humanitario respecto al derecho internacional de los derechos humanos, toda vez que cuando las circunstancias especiales del caso lo requieran habrá que darles aplicación a los derechos especiales y no al derecho internacional de los derechos humanos ${ }^{96}$.

Por su parte, Antônio Augusto Cançado-Trindade analiza que ni el derecho internacional humanitario ni el derecho internacional de los refugiados excluyen la aplicación de las normas básicas del derecho internacional de los derechos humanos. Las aproximaciones y convergencias entre estas tres vertientes amplían y fortalecen las vías de protección de la persona humana ${ }^{97}$.

94 Manfred Nowak, Introducción al régimen internacional de los derechos humanos, 61 (Agencia Sueca de Cooperación Internacional para el Desarrollo, Facultad de Derecho de la Universidad de Buenos Aires, UBA, Buenos Aires, 2009).

95 Christophe Swinarski, Principales nociones e institutos del Derecho Internacional Humanitario como sistema internacional de protección de la persona humana, 26-56 (Instituto Interamericano de Derechos Humanos, IIDH, San José de Costa Rica, 1990). Disponible en: http://www. derechoshumanos.unlp.edu.ar/assets/files/documentos/principales-nociones-e-institutos-delderecho-internacional-humanitario.pdf

96 Albert Galinsoga-Jordà, ed., El conflicto de Irak y el derecho internacional: el caso Couso, 485 (Editorial Universitat de Lleida, Santiago de Compostela, 2013).

97 Antônio Augusto Cançado-Trindade, Derecho internacional de los refugiados y derecho in- 
Adicionalmente, este jurista brasileño y juez de la Corte Internacional de Justicia, en La Haya, anota que las aproximaciones o convergencias entre la protección internacional de los derechos humanos y el derecho internacional de los refugiados ya no se limitan al plano conceptual o normativo, y se extienden también al plano operacional ${ }^{98}$. De esta forma, concluye, la doctrina y la práctica contemporánea admiten la aplicación simultánea o concomitante de normas de protección de las tres ramas del derecho internacional público ${ }^{99}$.

\section{LOS PRINCIPIOS VINCULADOS CON LOS DERECHOS DE LA NIÑEZ}

Como observamos anteriormente, desde el surgimiento del concepto de la niñez, la inclinación hacia la defensa de este grupo se extendió desde los primeros años en el reconocimiento de derechos, ya plasmados en otros instrumentos internacionales de derechos humanos a figuras jurídicas más específicas. En este sentido, se reconocieron principios rectores aplicables a este sector vulnerable de la población, que tienen un papel importante en la aplicación de los derechos. Sin embargo, el tema de los principios que aplican a los derechos de la niñez cuenta con un profundo vacío en el desarrollo de la fundamentación, interpretación y aplicación de estos. Esto debido a que adolecen de cierta indeterminación que requiere una ponderación en cada caso y que permite su vigencia abstracta en todo momento.

Algunos de los principios rectores que reconoce la Convención sobre Derechos del Niño son: la no discriminación, la cual garantiza la igualdad de protección de todos los niños y las niñas a

ternacional de los derechos humanos: aproximaciones y convergencias, 30 Revista Estudios Internacionales, 119-120, 321-349 (1997). Disponible en: http://www.revistaei.uchile.cl/index. $\mathrm{php} / \mathrm{REI} / \mathrm{article} / \mathrm{viewFile} / 15126 / 29127$

98 Antônio Augusto Cançado-Trindade, Derecho internacional de los refugiados y derecho internacional de los derechos humanos: aproximaciones y convergencias, 30 Revista Estudios Internacionales, 119-120, 321-349 (1997).

99 Antônio Augusto Cançado-Trindade, Derecho internacional de los refugiados y derecho internacional de los derechos humanos: aproximaciones y convergencias, 30 Revista Estudios Internacionales, 119-120, 321-349 (1997). 
eliminar la discriminación inherente a la aplicación de las leyes; el principio a la participación infantil, el cual abarca el derecho a la libertad de expresión, el acceso a la información y la oportunidad de expresar una opinión, es decir, participar activamente en todas las cuestiones que afecten su vida; $y$, por último, uno de los más importantes, el interés superior de la niñez.

El interés superior de la niñez ha experimentado diversos cambios al pasar de un mero derecho a un principio fundamental. Además, pasó de ser un concepto aplicado exclusivamente al derecho privado, principalmente al derecho de familia, a ser un concepto que de igual forma abarca el derecho público. Sobre este tema, Miguel Cillero ha enfatizado que una de las paradojas de la evolución del derecho de la infancia es que si bien, en el primer momento, se avanzó mediante el reconocimiento del carácter público de la protección de los intereses de los niños, posteriormente ha sido necesario reconocer la necesidad de limitar las facultades del Estado para intervenir en los asuntos de la infancia, lo que ha debido hacerse con especial preocupación en el ámbito de la aplicación abierta o encubierta de mecanismos del sistema punitivo hacia los niños ${ }^{100}$.

Ahora bien, la evolución que tuvo este concepto también trascendió desde un concepto de aplicación local o doméstica hasta el ámbito internacional. Como vimos anteriormente, este principio fue reconocido, internacionalmente, por primera vez por la Declaración de Derechos del Niño de 1959 y posteriormente fue rescatado por la Convención sobre Derechos del Niño de 1989.

Por otro lado, no solo estos instrumentos internacionales hacen referencia al interés superior de la niñez, hay otros que también lo consignan en su texto, como la Convención sobre la Eliminación de todas las formas de Discriminación contra

100 Miguel Cillero-Bruñol, El interés superior del niño en el marco de la Convención Internacional sobre los Derechos del Niño, en Infancia, Ley y Democracia en América Latina, 69-85 (Emilio García-Méndez \& Mary Belloff, comps., Ediciones Temis, Ediciones Desalma, Bogotá, Buenos Aires, 1998). 
la Mujer (CEDAW) ${ }^{101}$ y la Convención Internacional sobre la Eliminación de todas las Formas de Discriminación Racial ${ }^{102}$. A pesar de su reconocimiento internacional, la gran preocupación sobre este concepto es que en ningún tratado internacional contemplan los elementos distintivos o esenciales que rigen este principio, incluso para algunos autores esta situación es un problema jurídico, debido a que su indeterminación permite un amplio margen de discrecionalidad que pudiera ser abusiva ${ }^{103}$.

Por su parte, Miguel Cillero-Bruñol ha expresado que, por lo general, se cree que el interés superior de la niñez es una directriz vaga, indeterminada y sujeta a múltiples interpretaciones, tanto en el carácter jurídico como psicosocial, que constituiría una especie de excusa para tomar decisiones al margen de los derechos reconocidos en razón de un etéreo interés superior extrajurídico ${ }^{104}$. Para Andrea Charlow, debido a que el interés superior de la niñez es un concepto vago, las predicciones sobre el sentido y el alcance legal y científico, por lo general, son contrarias a la protección internacional, por lo tanto, están sujetas a abusos tanto por los jueces que lo determinan como por los padres que lo utilizan para sus propios intereses ${ }^{105}$.

101 Organización de las Naciones Unidas, Asamblea General, Convención sobre la Eliminación de todas las formas de Discriminación contra la Mujer (CEDAW), Resolución 34/180, 18 de diciembre de 1979. Disponible en: http://www.acnur.org/fileadmin/scripts/doc.php?file=fileadmin/ Documentos/BDL/2001/0031

102 Organización de las Naciones Unidas, Asamblea General, Convención Internacional sobre la Eliminación de todas las Formas de Discriminación Racial, Resolución 2106 A (XX), 21 de diciembre de 1965. Disponible en: http://www.ohchr.org/SP/ProfessionalInterest/Pages/CERD. aspx

103 Farith Simón-Campaña, Interés superior del menor: técnicas de reducción de la discrecionalidad abusiva (Tesis doctoral, Universidad de Salamanca, 2013). Disponible en: https:/gredos. usal.es/jspui/bitstream/10366/124216/1/DDP_Sim\%C3\%B3nCampa\%C3\%B1a_Farith_Tesis. pdf. Miguel Cillero-Bruñol, El interés superior del niño en el marco de la Convención Internacional sobre los Derechos del Niño, en Infancia, Ley y Democracia en América Latina, 69-85 (Emilio García-Méndez \& Mary Belloff, comps., Ediciones Temis, Ediciones Desalma, Bogotá, Buenos Aires, 1998).

104 Miguel Cillero-Bruñol, El interés superior del niño en el marco de la Convención Internacional sobre los Derechos del Niño, en Infancia, Ley y Democracia en América Latina, 69-85 (Emilio García-Méndez \& Mary Belloff, comps., Ediciones Temis, Ediciones Desalma, Bogotá, Buenos Aires, 1998).

105 Andrea Charlow, Awarding Custody: the Best Interest of the Child and Other Fictions, 5 Yale Law \& Policy Review, 2, 267-290 (1986). Disponible en: http://digitalcommons.law.yale.edu/ cgi/viewcontent.cgi?article $=1103 \&$ context $=$ ylpr 
Geraldine van Bueren explica que, debido a la indeterminación del concepto, es un principio jurídico de interpretación que es desarrollado a partir de una perspectiva compasiva y autoimpuesta su limitación por el poder de los adultos ${ }^{106}$.

Debido a esta ausencia de contenido legal, el Comité DN comenzó a sentar las bases del contenido de este concepto. Este ejercicio de interpretación sentó precedente, con la finalidad de contribuir a la satisfacción del principio de seguridad jurídica, en materia de derecho de familia, o en todo ámbito del derecho que sea aplicable. Esto contribuiría a disminuir el nivel de ambigüedad del concepto en estudio y favorecería una mejor y mayor protección de los derechos de los niños ${ }^{107}$.

Otro de los problemas que enfrenta este concepto es su naturaleza jurídica, es decir, si este es un derecho, un principio o simplemente una directriz. Esto debido a que varios autores, como Miguel Cillero o Mary Belloff, se refieren a este concepto como un principio; mientras que otros lo hacen como si fuera un derecho ${ }^{108}$; y para algunos otros juristas este representa solo una orientación sobre una decisión jurídica ${ }^{109}$.

Este problema se deriva de la falta de claridad y de uniformidad de la naturaleza jurídica de esta noción. Las repercusiones de esta confusión jurídica pueden afectar las decisiones que adopten los jueces, las autoridades administrativas, las políticas públicas, los abogados litigantes y los académicos, entre otros. Uno de los efectos jurídicos de los principios es que pueden llegar a suplir las lagunas existentes en el derecho convencional o

106 Geraldine van Bueren, The International Law on the Rights of the Child, 234 (Martinus Nijhoff, Dordrecht, Netherlands, 1995).

107 Susy Muñoz-Merkle, Concepto de interés superior del niño en el Comité de Derechos del Niño, en La internacionalización del derecho público, 205-220, 209 (Manuel Antonio Núñez-Poblete, ed., Thomson Reuters, Santiago, 2015).

108 Gloria Baeza-Concha, El interés superior del niño: derecho de rango constitucional, su recepción en la legislación nacional y aplicación en la jurisprudencia, 28 Revista Chilena de Derecho, 2, 355-362 (2001). Disponible en: https://repositorio.uc.cl/bitstream/ handle/11534/14905/000334708.pdf?sequence=1

109 Susan Turner-Saelzer, Sentencia sobre determinación de la titularidad del cuidado personal de los hijos menores: Corte de Apelaciones de Santiago, 17 Revista de Derecho, 1, 273-278 (2004). Disponible en: http://www.scielo.cl/scielo.php?script=sci_arttext\&pid $=$ S0718-09502004000200012. Francisco Rivero-Hernández, El interés superior del menor, 26 (Editorial Dykinson, Madrid, 2000). 
consuetudinario. Aunque los principios constituyen una fuente subsidiaria, tienen un indudable carácter autónomo, desde el momento en que poseen una vigencia propia ${ }^{110}$.

En este contexto, María Josefa Méndez-Costa dice que el rol de los principios jurídicos, en especial en el derecho de familia, emanan de la afectio familia. Por lo tanto y de conformidad con Ronald Dworkin, son estándares que responden a una exigencia de justicia, pero además con un fuerte contenido ontológico pues coinciden con los derechos fundamentales. La autora argentina concluye que el interés superior se identifica con los derechos humanos del niño con eficacia interpretativa, programática y de efectividad inmediata ${ }^{111}$.

En el mismo sentido, Miguel Cillero insiste en que el interés superior de la niñez es un principio jurídico que ha evolucionado conjuntamente con el reconocimiento progresivo de los derechos de la niñez, de modo que se ha alcanzado una construcción jurídica con un importante grado de desarrollo, por lo que el concepto debe ser interpretado a la luz de este nuevo contexto ${ }^{112}$. En este sentido, este autor reconoce que no se trata solo de un principio jurídico; también lo describe como un principio jurídico garantista, debido a que permite la resolución de conflicto de derechos y a la vez promueve su protección efectiva ${ }^{113}$.

En este sentido, varias resoluciones de tribunales nacionales han utilizado esta noción como una directriz más que un derecho o principio. Por ejemplo, el Tribunal Supremo de España señaló que "estos principios, considerados en abstracto, constituyen principios de fin o directrices en cuanto no establecen mandatos genéricos por razón del objeto, sino por razón del fin"114. Por

110 Edmundo Vargas-Carreño, Derecho internacional público: de acuerdo a las normas y prácticas que rigen en el siglo XXI, 100 (Editorial Jurídica de Chile, Santiago, 2007).

111 María Josefa Méndez-Costa, Los principios jurídicos en las relaciones de familia, 28-29 (Buenos Aires, Editores Rubinzal-Culzoni, 2006).

112 Miguel Cillero-Bruñol, El interés superior del niño en el marco de la Convención Internacional sobre los Derechos del Niño, en Infancia, Ley y Democracia en América Latina, 69-85 (Emilio García-Méndez \& Mary Belloff, comps., Ediciones Temis, Ediciones Desalma, Bogotá, Buenos Aires, 1998).

113 Ibid., p. 8.

114 España, Tribunal Supremo, Sentencia STS 5817/2009, 31 de julio de 2009. Juez ponente Juan Antonio Xiol-Ríos, FJ6. Disponible en: http://www.rediuris.com/documentacion/161.pdf 
lo tanto, se puede observar que elevar el interés superior de la niñez a una consideración primordial es relevante para entender el significado que este tiene en las decisiones que la afectan. A partir de esta consideración, la siguiente etapa es fijar un estándar jurídico que ayuda a visualizar el sentido y la naturaleza de este concepto no determinado por el derecho internacional de los derechos de la niñez. 
CONCLUSIÓN

La evolución histórica en el reconocimiento de los derechos de la infancia pasó desde el olvido hasta ser actualmente uno de los temas de mayor preocupación internacional. Esta evolución no fue producto de la razón jurídica, sino más bien estuvo motivada por razones de carácter humanitario y social. Este reconocimiento jurídico se dio cuando se comprendió la necesidad de brindar protección jurídica a aquellas personas por su condición de vulnerabilidad y madurez.

Esta evolución no culminó con la adopción de la Convención sobre Derechos del Niño, sino que este constituyó un hito trascendental de protección de los derechos de la infancia. Además, como hemos observado, los derechos de la niñez continúan consolidándose y transformándose no solo desde el campo del derecho internacional, sino también desde la consolidación doctrinaria.

En la actualidad, se han vencido algunos obstáculos y barreras jurídicas que impiden una correcta implementación de las normas internacionales en su conjunto. En este sentido, el interés superior de la niñez al incorporarse en los instrumentos internacionales relacionados con la infancia como principio fundamental de los derechos antes mencionados, provocó que este sea ubicado en el centro de decisión que afecte cualquier derecho del niño. Además, ante esta evolución constante del derecho internacional público, podemos señalar que este principio también encuentra espacio en otras áreas, como el humanitario, el de refugiados y el de los derechos humanos.

Sin embargo, como observamos en este artículo, este principio nació siendo un concepto jurídicamente indeterminado, debido a la falta de definición y precisión y, por lo tanto, da la posibilidad de que los órganos encargados de su aplicación tengan un amplio margen de discrecionalidad. Aunque para algunos autores la discrecionalidad sea necesaria para darles contenido concreto y adaptabilidad del principio a circunstancias concretas, la realidad demuestra que, también, pudiera ser todo lo 
contrario, es decir, puede caer en la discrecionalidad abusiva, ya que puede ser contraria a la luz del derecho internacional de los derechos humanos. 


\section{BIBLIOGRAFÍA}

\section{Libros}

Adams, Paul; Berg, Leila; Berger, Nan; Duane, Michael; Neill, Alexander Sutherland \& Ollendorff, Robert, Los derechos de los niños, hacia la liberalización del niño (Julián Hall, comp., María Aurora Reyes de Baroco, trad., Editorial Extemporáneos, México, 1979).

Bidart-Campos, Germán J., Teoría general de los derechos humanos (Astrea, Buenos Aires, 1991).

Bobbio, Norberto, El tiempo de los derechos (Editorial Sistema, Madrid, 1991).

Bueren, Geraldine van, The International Law on the Rights of the Child (Martinus Nijhoff, Dordrecht, Netherlands, 1995).

Cançado-Trindade, Antônio Augusto, El derecho internacional de los derechos humanos en el siglo XXI ( $2^{\mathrm{a}}$ ed., Editorial Jurídica de Chile, Santiago, 2001).

Comisión Interamericana de Derechos Humanos y Relatoría sobre Derechos de la Niñez, Justicia juvenil y derechos humanos en las Américas (OEA/Ser.L/V/II, Doc. 78, 2011). Disponible en: https://www.oas.org/es/cidh/infancia/docs/pdf/ justiciajuvenil.pdf

Coronado-Buitrago, María Jesús, Compatibilidad del derecho internacional con los derechos a favor de la niñez: evolución jurídica de los derechos de la infancia, en Exposición de los derechos del niño (Carmen Sánchez-Moro, coord., Ministerio de Asuntos Sociales, Madrid, 1989).

Dávila-Balsera, Paulí \& Naya-Garmendia, Luis María, comps., Derechos de la infancia y educación inclusiva en América Latina (Granica, Buenos Aires, 2011).

Feinberg, Joel, Rights, Justice and the Bounds of Liberty: Essays in Social Philosophy (Princeton University Press, Princeton, New Jersey, 1980).

Frutos, Pedro, Compendio de derecho internacional público (Biblioteca Jurídica Argentina, Buenos Aires, 1932).

Galinsoga-Jordà, Albert, ed., El conflicto de Irak y el derecho internacional: el caso Couso (Editorial Universitat de Lleida, Santiago de Compostela, 2013).

García-Cano, Sandra, Protección del menor y cooperación internacional entre autoridades (Colex, Madrid, 2003).

Garibo-Peyró, Ana Paz, Los derechos de los niños: una fundamentación (Ministerio del Trabajo y Asuntos Sociales, Madrid, 2004).

Garro, Cristóbal R., Declaración Universal de Derechos Humanos, Abriendo surcos (Depalma, Buenos Aires, 1985).

Gómez-Robledo, Antonio, Fundadores del derecho internacional. Vitoria, Gentili, Suárez, Grocio (Universidad Nacional Autónoma de México, UNAM, Instituto de Investigaciones Jurídicas, IIJ, México, 1992). Disponible en: https://biblio. juridicas.unam.mx/bjv/detalle-libro/383-fundadores-del-derecho-internacionalvitoria-gentili-suarez-grocio 
González-Contró, Mónica, Derecho de familia en México (Instituto de Investigaciones Jurídicas de la Universidad Nacional Autónoma de México, UNAM, México, 2010).

González-Contró, Mónica; Padrón-Innamorato, Mauricio; Márquez-Gómez, Daniel; Arroyo-Casanova, Rosío \& Melgar-Manzanilla, Pastora, Propuesta teóricometodológica para la armonización legislativa desde el enfoque de derechos de niñas, niños y adolescentes (Instituto de Investigaciones Jurídicas de la Universidad Nacional Autónoma de México, UNAM, México, 2012).

Grocio, Hugo, Del derecho de la guerra y de la paz (Jaime Torrubiano-Ripoll, trad., Editorial Reus, Madrid, 1925). Disponible en: http://fama2.us.es/fde/ocr/2010/ delDerechoDeLaGuerraYDeLaPazT1.pdf

Jiménez de Aréchaga, Eduardo, Derecho constitucional de las Naciones Unidas: comentario teórico-práctico de la Carta (Escuela de Funcionarios Internacionales, Madrid, 1958).

Le Gal, Jean, Los derechos del niño en la escuela: una educación para la ciudadanía (Francesc Massana, trad., Editorial Graó, Barcelona, 2005).

López-Sánchez, Cristina, La responsabilidad civil del menor ( $2^{\mathrm{a}}$ ed., Dykinson, Madrid, 2003).

Méndez-Costa, María Josefa, Los principios jurídicos en las relaciones de familia (Buenos Aires, Editores Rubinzal-Culzoni, 2006).

Nowak, Manfred, Introducción al régimen internacional de los derechos humanos (Agencia Sueca de Cooperación Internacional para el Desarrollo, Facultad de Derecho de la Universidad de Buenos Aires, UBA, Buenos Aires, 2009).

Peces-Barba Martínez, Gregorio, Curso de derechos fundamentales: teoría general (Universidad Carlos III de Madrid, Boletín Oficial del Estado, Madrid, 1995).

Riquelme-Cortado, Rosa, Derecho internacional: entre un orden global y fragmentado (Editorial Biblioteca Nueva, Madrid, 2005).

Rivero-Hernández, Francisco, El interés del menor (Dykinson, Madrid, 2007).

Salmón, Elizabeth, Introducción al derecho internacional humanitario (Comité Internacional de la Cruz Roja, CICR, Lima, 2004). Disponible en: http://idehpucp.pucp.edu. pe/images/publicaciones/introduccion_al_derecho_internacional_humanitario.pdf

Swinarski, Christophe, Principales nociones e institutos del Derecho Internacional Humanitario como sistema internacional de protección de la persona humana (Instituto Interamericano de Derechos Humanos, IIDH, San José de Costa Rica, 1990). Disponible en: http://www.derechoshumanos.unlp.edu.ar/assets/files/documentos/ principales-nociones-e-institutos-del-derecho-internacional-humanitario.pdf

Torres-Perea, José Manuel de, Interés del menor y derecho de familia: una perspectiva multidisciplinar (Iustel, Madrid, 2009).

Vargas-Carreño, Edmundo, Derecho internacional público: de acuerdo a las normas y prácticas que rigen en el siglo XXI (Editorial Jurídica de Chile, Santiago, 2007).

Vasak, Karel, Las dimensiones internacionales de los derechos humanos, Vol. I (Hernán Sabaté y María José Rodellar, trads., Editorial Serbal, Barcelona, 1984).

Ward, John Towers, Popular Movements c. 1830-1850 (John Towers Ward, ed., MacMillan, London, 1970). 
Ward, John Towers, The Factory Movement, 1830-1855 (MacMillan, London, 1962).

\section{Colaboración en obras colectivas}

Cillero-Bruñol, Miguel, El interés superior del niño en el marco de la Convención Internacional sobre los Derechos del Niño, en Infancia, Ley y Democracia en América Latina, 69-85 (Emilio García-Méndez \& Mary Belloff, comps., Ediciones Temis, Ediciones Desalma, Bogotá, Buenos Aires, 1998). Disponible en: https://ecaths1. s3.amazonaws.com/tfi/1011729881.texto\%20CILLERO\%20BRU\%C3\%91OL.pdf

Grossman, Claudio, Reflexiones sobre el sistema interamericano de protección y promoción de los derechos humanos, en La Corte y el Sistema Interamericano de Derechos Humanos (Rafael Nieto-Navia, ed., Corte Interamericana de Derechos Humanos, San José, 1997).

Muñoz-Merkle, Susy, Concepto de interés superior del niño en el Comité de Derechos del Niño, en La internacionalización del derecho público, 205-220 (Manuel Antonio Núñez-Poblete, ed., Thomson Reuters, Santiago, 2015).

Nikken, Pedro, El concepto de derechos humanos, en Estudios básicos de derechos humanos, tomo I, 15-38 (Instituto Interamericano de Derechos Humanos, IIDH, San José de Costa Rica, 1994). Disponible en: http://www.iidh.ed.cr/IIDH/media/2250/ estudios-basicos-01-1994.pdf

Paul-Ochotorena, Joaquín de, Diferentes situaciones de desprotección infantil, en Manual de protección infantil (María Ignacia Arruabarrena-Madariaga \& Joaquín de Paul-Ochotorena, Masson, Barcelona, 2001).

Piquer-Marí, José Miguel, Apuntes generales sobre la situación jurídica y la protección del menor en el derecho romano, en La protección del menor, 339-371 (Antonio Vallés, dir., Tirant lo Blanch, Valencia, 2009).

\section{Revistas}

Ariès, Philippe, La infancia, 281 Revista de Educación, 5-17 (1986). Disponible en: http://www.mecd.gob.es/revista-de-educacion/numeros-revista-educacion/ numeros-anteriores/1986/re281.html, http://www.mecd.gob.es/dctm/revista-deeducacion/numeros-completos/re28100507.pdf?documentId=0901e72b813c4502

Baeza-Concha, Gloria, El interés superior del niño: derecho de rango constitucional, su recepción en la legislación nacional y aplicación en la jurisprudencia, 28 Revista Chilena de Derecho, 2, 355-362 (2001). Disponible en: https://repositorio.uc.cl/ bitstream/handle/11534/14905/000334708.pdf?sequence=1

Cançado-Trindade, Antônio Augusto, Derecho internacional de los refugiados y derecho internacional de los derechos humanos: aproximaciones y convergencias, 30 Revista Estudios Internacionales, 119-120, 321-349 (1997). Disponible en: http:// www.revistaei.uchile.cl/index.php/REI/article/viewFile/15126/29127

Castán-Vázquez, José María, La reforma de la adopción en el derecho francés, 3 Anuario de Derecho Civil, 821-823 (1963). Disponible en: https://www.boe.es/ 
publicaciones/anuarios_derecho/abrir_pdf.php?id=ANU-C-1963-30082100823

Charlow, Andrea, Awarding Custody: the Best Interest of the Child and Other Fictions, 5 Yale Law \& Policy Review, 2, 267-290 (1986). Disponible en: http://digitalcommons. law.yale.edu/cgi/viewcontent.cgi?article=1103\&context=ylpr

Dávila-Balsera, Paulí \& Naya-Garmendia, Luis María, La evolución de los derechos de la infancia: una visión internacional, 7 Revista Encounters on Education, 71-93 (2006). Disponible en: http://ojs.library.queensu.ca/index.php/encounters/article/ view/597/3498

Goonesekere, Savitri, The Best Interests of the Child: South Asian Perspective, 8 International Law Policy Family, 1, 117-149 (1994). Disponible en: http://digital.lib. ou.ac.lk/docs/bitstream/701300122/1322/1/The\%20Best\%20Interest $\% 20$ of $\% 20$ the $\% 20$ Child.pdf

Gros-Espiell, Héctor, Los derechos humanos y el derecho internacional, 1968-1977, 10 Jurídica, Anuario del Departamento de Derecho de la Universidad Iberoamericana, tomo II, 152-166 (1978). Disponible en: http://historico.juridicas.unam.mx/publica/ librev/rev/jurid/cont/10/pr/pr33.pdf

Longobardo, Tilde, La Convenzione Internazionale sui Diritti del Fanciullo, New York, 20 novembre 1989, 1 Il Diritto di Famiglia e delle Persone, 370-427 (1991).

López-Contreras, Rony Eulalio, Interés superior de los niños y niñas: definición y contenido, 13 Revista Latinoamericana de Ciencias Sociales, Niñez y Juventud, 1, 51-70 (2015). Disponible en: http://revistaumanizales.cinde.org.co/index.php/ Revista-Latinoamericana/article/view/1635/532

Nikken, Pedro, Los derechos del niño, de los ancianos y de la mujer: su protección internacional, 4 Revista IIDH/Instituto Interamericano de Derechos Humanos, 15 42 (1986). Disponible en: http://www.iidh.ed.cr/IIDH/media/1609/revista-iidh4.pdf

Ravetllat-Ballesté, Isaac \& Pinochet-Olave, Ruperto, El interés superior del niño en el marco de la Convención Internacional sobre los Derechos del Niño y su configuración en el derecho civil chileno, 42 Revista Chilena de Derecho, 3, 903-934 (2015). Disponible en: https://dialnet.unirioja.es/ejemplar/427895

Rollet, Catherine, La santé et la protection de l'enfant vues à travers les Congrès internationaux (1880-1920), 101 Annales de Démographie Historique, 1, 97-116 (2001). Disponible en: https://www.cairn.info/revue-annales-de-demographie-historique-2001-1-page-97.htm

San Miguel, Manuela, Por la liberación del niño... Jules Vallès, 1 Revista Pedagogía de la Universidad de Salamanca, 57-67 (1985). Disponible en: http://revistas.usal. es/index.php/0214-3402/article/view/516/689

Turner-Saelzer, Susan, Sentencia sobre determinación de la titularidad del cuidado personal de los hijos menores: Corte de Apelaciones de Santiago, 17 Revista de Derecho, 1, 273-278 (2004). Disponible en: http://www.scielo.cl/scielo.php?script=sci_ar ttext\&pid=S0718-09502004000200012 
Simón-Campaña, Farith, Interés superior del menor: técnicas de reducción de la discrecionalidad abusiva (Tesis doctoral, Universidad de Salamanca, 2013). Disponible en: https://gredos.usal.es/jspui/bitstream/10366/124216/1/DDP_ Sim $\%$ C3\%B3nCampa $\%$ C3\%B1a_Farith_Tesis.pdf

\section{Jurisprudencia internacional}

Corte Interamericana de Derechos Humanos, Corte IDH, Opinión Consultiva OC-17/02, Serie A 17, Condición jurídica y derechos humanos del niño, 28 de agosto de 2002. Disponible en: http://www.corteidh.or.cr/docs/opiniones/seriea_17_esp.pdf

European Court of Human Rights, ECHR, Case of Titina Loizidou v. Turkey, 15318/89, Preliminary Objections, Judgment, 23 February 1995. Disponible en: http://www. refworld.org/docid/402a07c94.html

\section{Tratados internacionales}

Conferencia de La Haya de Derecho Internacional Privado, Convenio relativo a la Protección del Niño y la Cooperación en Materia de Adopción Internacional, La Haya, 29 de mayo de 1993. Disponible en: https://www.hcch.net/es/instruments/ conventions/full-text $/$ ?cid=69

Consejo Federal suizo, Convenio de Ginebra, 22 de agosto de 1864 para el mejoramiento de la suerte de los militares heridos en los ejércitos en campaña. Disponible en: https://www.icrc.org/spa/resources/documents/treaty/treaty-1864-genevaconvention-1.htm

Liga de las Naciones, Declaración sobre Derechos de los Niños o Declaración de Ginebra, 26 de septiembre de 1924. Disponible en: http://ojd.org.do/Normativas/Penal\%20 NNA/Instrumentos\%20internacionales/Declaracion\%20de\%20Ginebra\%201924. pdf, http://www.humanium.org/es/declaration-de-geneve-du-26-septembre-1924/

Organización de Estados Americanos, OEA, Convención Americana sobre Derechos Humanos, San José, Costa Rica, 7 al 22 de noviembre de 1969. Disponible en: https://www.oas.org/dil/esp/tratados_b-32_convencion_americana_sobre_derechos_humanos.htm

Organización de Estados Americanos, OEA, Reglamento de la Comisión Interamericana de Derechos Humanos, aprobado por la Comisión en su $137^{\circ}$ período ordinario de sesiones, 28 de octubre al 13 de noviembre de 2009. Disponible en: http://www. oas.org/es/cidh/mandato/Basicos/reglamentoCIDH.asp

Organización de las Naciones Unidas, Asamblea General, Carta de las Naciones Unidas, San Francisco, 26 de junio de 1945. Disponible en: http://www.un.org/es/ charter-united-nations/index.html

Organización de las Naciones Unidas, Asamblea General, Comité sobre Derechos del Niño, Protocolo facultativo de la Convención sobre los Derechos del Niño relativo a 
un procedimiento de comunicaciones, Asamblea General, Resolución A/Res/66/138 (2011). Disponible en: http://www.acnur.org/t3/fileadmin/Documentos/Proteccion/ Buenas_Practicas/9532.pdf?view=1

Organización de las Naciones Unidas, Asamblea General, Convención de Viena sobre el derecho de los tratados, Viena, 23 de mayo de 1969. Disponible en: http://www. oas.org/xxxivga/spanish/reference_docs/convencion_viena.pdf, http://legal.un.org/ diplomaticconferences/lawoftreaties-1969/docs/english/confdocs/a_conf_39_27.pdf

Organización de las Naciones Unidas, Asamblea General, Convención Internacional sobre la Eliminación de todas las Formas de Discriminación Racial, Resolución 2106 A (XX), 21 de diciembre de 1965. Disponible en: http://www.ohchr.org/SP/ ProfessionalInterest/Pages/CERD.aspx

Organización de las Naciones Unidas, Asamblea General, Convención sobre Derechos del Niño, adoptada y abierta a la firma y ratificación por la Asamblea General en su Resolución 44/25, 20 de noviembre de 1989, entrada en vigor 2 de septiembre de 1990. Disponible en: http://www.hchr.org.co/documentoseinformes/documentos/ html/pactos/conv_derechos_nino.html

Organización de las Naciones Unidas, Asamblea General, Convención sobre el consentimiento para el matrimonio, la edad mínima para contraer matrimonio y el registro de los matrimonios, Resolución 1763 A (XVII), 7 de noviembre de 1962. Disponible en: http://www.ohchr.org/SP/ProfessionalInterest/Pages/MinimumAgeForMarriage.aspx

Organización de las Naciones Unidas, Asamblea General, Convención sobre el Estatuto de los Refugiados, adoptada en Ginebra, Suiza, el 28 de julio de 1951 por la Conferencia de Plenipotenciarios sobre el Estatuto de los Refugiados y de los Apátridas (Naciones Unidas), convocada por la Asamblea General en su Resolución 429 (V), 14 de diciembre de 1950. Disponible en: http://www.acnur.org/fileadmin/scripts/ doc.php?file=fileadmin/Documentos/BDL/2001/0005

Organización de las Naciones Unidas, Asamblea General, Convención sobre la Eliminación de todas las formas de Discriminación contra la Mujer (CEDAW), Resolución 34/180, 18 de diciembre de 1979. Disponible en: http://www.acnur.org/fileadmin/ scripts/doc.php?file=fileadmin/Documentos/BDL/2001/0031

Organización de las Naciones Unidas, Asamblea General, Declaración de los Derechos del Niño, Resolución 1386 (XIV), 14 UN GAOR Supp. (No. 16), 19, ONU Doc. A/4354 (1959), 20 de noviembre de 1959. Disponible en: https://www.oas.org/dil/ esp/Declaraci\%C3\%B3n\%20de\%20los\%20Derechos\%20del\%20Ni\%C3\%B1o\%20 Republica\%20Dominicana.pdf

Organización de las Naciones Unidas, Asamblea General, Declaración Universal de los Derechos Humanos, adoptada en la Resolución 217 A (III), 10 de diciembre de 1948. Disponible en: http://www.un.org/es/universal-declaration-human-rights/

Organización de las Naciones Unidas, Asamblea General, Directrices de las Naciones Unidas para la Prevención de la Delincuencia Infantil (Directrices de Riad, 1990), Resolución 45/112, 14 de diciembre de 1990. Disponible en: http://www.un.org/es/ comun/docs/?symbol=\%20A/RES/45/112\&Lang=S

Organización de las Naciones Unidas, Asamblea General, Recomendaciones sobre el Consentimiento para el Matrimonio, la Edad Mínima para Contraer Matrimonio y 
Registro de los Matrimonios, Resolución 2018 (XX) de la Asamblea General, 1 de noviembre de 1965. Disponible en: http://www.ohchr.org/SP/ProfessionalInterest/ Pages/RecommendationOnConsentToMarriage.aspx

Organización de las Naciones Unidas, Asamblea General, Reglas Mínimas de las Naciones Unidas para la Administración de Justicia de Menores, A.G. res. 40/33, anexo, 40 U.N. GAOR Supp. (No. 53) p. 207, ONU Doc. A/40/53 (1985) (Reglas de Beijing, 1985), Beijing, 29 de noviembre de 1985. Disponible en: https://www. unicef.org/panama/spanish/7972.htm

Organización de las Naciones Unidas, Asamblea General, Reglas Mínimas de las Naciones Unidas para la Protección de los Menores Privados de la Libertad, Resolución 45/113 (Reglas de Tokio, 1990), Tokio, 14 de diciembre de 1990. Disponible en: http://www.un.org/es/comun/docs/?symbol=\%20A/RES/45/113\&Lang=S

Organización de las Naciones Unidas, Asamblea General, Protocolo Facultativo de la Convención sobre los Derechos del Niño relativo a la Participación de Niños en Conflictos Armados, Resolución A/RES/54/263, New York, 25 de mayo de 2000. Disponible en: http:/www.un.org/es/comun/docs/?symbol=A/RES/54/263

Organización de las Naciones Unidas, Asamblea General, Protocolo Facultativo de la Convención sobre los Derechos del Niño relativo a la Venta de Niños, la Prostitución Infantil y la Utilización de Niños en la Pornografía, Resolución A/RES/54/263, New York, 25 de mayo de 2000. Disponible en: http://www.ohchr.org/SP/ProfessionalInterest/Pages/OPSCCRC.aspx

Organización Internacional del Trabajo, OIT, Convenio C138, Convenio sobre la edad mínima de admisión al empleo, Ginebra, 26 de junio de 1973. Disponible en: http://www.ilo.org/dyn/normlex/es/f?p=NORMLEXPUB:12100:0::NO: :P12100_ILO_CODE:C138

Organización Internacional del Trabajo, OIT, Convenio C182, Convenio sobre la prohibición de las peores formas de trabajo infantil y la acción inmediata para su eliminación, Ginebra, 17 de junio de 1999. Disponible en: http://www.ilo.org/dyn/ normlex/es/f?p=1000:12100:0::NO::P12100_ILO_CODE:C182

\section{Normatividad internacional}

Francia, Code Civil des Français, 21 mars de 1804. Disponible en: http:/gallica.bnf.fr/ ark:/12148/bpt6k1061517

Francia, Loi du 22 mars de 1841, relative au travail des enfants employés dans les manufactures, usines ou ateliers. Disponible en: http://travail-emploi.gouv.fr/IMG/ pdf/loi_22_mars_1841-2.pdf

Francia, Loi du 28 mars de 1882, portant sur l'organisation de l'enseignement primaire. Disponible en: https://www.legifrance.gouv.fr/affichTexte.do;jsessionid=81B65BF 14727E4047256DD3714A3902E.tpdjo16v_2?cidTexte=LEGITEXT000006070887 \&dateTexte $=19981221$

Francia, Loi du 24 juillet de 1889, sur la protection des enfants maltraités ou moralement abandonnés, placement des mineurs, action educative en milieu ouvert. 


\section{Jurisprudencia internacional}

España, Tribunal Supremo, Sentencia STS 5817/2009, 31 de julio de 2009, juez ponente Juan Antonio Xiol-Ríos, FJ6. Disponible en: http://www.rediuris.com/documentacion/161.pdf

\section{Informes, reportes}

Fondo de Naciones Unidas para la Infancia, UNICEF, Estado mundial de la infancia: Edición Especial. Conmemoración de los 20 años de la Convención sobre los Derechos del Niño (UNICEF, Nueva York, 2009). Disponible en: https://www.unicef.org/ spanish/publications/files/SOWC_Spec._Ed._CRC_Main_Report_SP_1201009.pdf

\section{Casos internacionales}

Rex v. Delaval, 1763.

Rex v. De Manneville, 1804.

Blissets, 1774.

\section{Comunicados de prensa}

Organización de Naciones Unidas, Centro de Noticias, Con Somalia, 196 países han ratificado ya la Convención sobre los Derechos del Niño (1 de octubre de 2015). Disponible en: http://www.un.org/spanish/News/story.asp?NewsID=33493\#. VusWefnhCUk, http://www.un.org/spanish/News/story.asp?NewsID=33493\#. WRiyP2jhA65 